\title{
Assessment of a Lagrangian model using trajectories of oceanographic drifters and fishing devices in the Tropical Atlantic Ocean
}

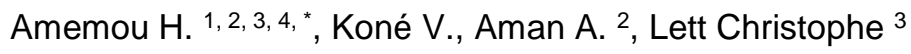

${ }^{1}$ Centre de Recherches Océanologiques (CRO), 29 Rue des Pêcheurs, BPV 18, Abidjan, Côte d'Ivoire

${ }^{2}$ Laboratoire de Physique de l'Atmosphére et Mécanique des fluides, LAPA-MF, Université Félix

Houphouet Boigny, Côte d'Ivoire

3 MARBEC, Univ Montpellier, CNRS, IFREMER, IRD, Séte, France

${ }^{4}$ Sorbonne Université, IRD, Unité de Modélisation Mathématique et Informatique des Systémes

Complexes, UMMISCO, F-93143, Bondy, France

* Corresponding author : H. Amemou, email address : yagoamemou@gmail.com

\begin{abstract}
:
In the Tropical Atlantic Ocean, we assessed the accuracy of a Lagrangian model (Ichthyop) forced with velocity fields from a hydrodynamical model (CROCO) and two different remote sensing products (GlobCurrent and OSCAR) using trajectories of oceanographic drifters. Additionally, we evaluated the possibility to expand the drifters data using trajectories of GPS-buoy equipped drifting Fish Aggregating Devices (FADs). Tehe observed and simulated trajectories were compared in terms of spatial distribution, velocity distribution and a nondimensional skill score. For the drifters and FADs, the GlobCurrent and OSCAR products lead to similar performances as the CROCO model-ouputs in the broad studied domain. In the Gulf of Guinea, however, the CROCO model performed significantly better than the other two because the parent solution of CROCO benefited from its communication with a child grid of finer resolution in this region. On average, the simulations lead to an underestimation of the drifter and FAD velocities, likely because the spatial resolutions of the forcing products were insufficient and the time frequency at which they were produced were too low to resolve the relevant oceanic processes properly. We found a low skill for all models to simulate FAD trajectories, possibly because of the devices vertical structure that prevent FADs from drifting like water parcels. Our results therefore suggest that in the Tropical Atlantic the FAD dataset may not be appropriate to use for corroborating Lagrangian simulations.
\end{abstract}

\section{Highlights}

- Assessement of the accuracy of a Lagrangian model forced with different velocity fields using drifters and Fish Aggregating Devices (FADs). CROCO, OSCAR and GlobCurrent have the same performance. CROCO is better in the Gulf of Guinea than the satellite derived currents. The simulations underestimate the drifters and FADs velocities. FADs may not be appropriate to use for corroborating Lagrangian simulations.

Keywords : Drifter, fish aggregating device, particle, trajectory, velocity, model performance 


\section{Introduction}

The Tropical Atlantic Ocean circulation is particularly challenging to study due to the presence of strong surface currents and undercurrents displaying a large spatial and temporal variability (Blanke and Delecluse, 1993). It is

5 also a region of deepwater resurgences, leading to coastal upwelling (Broecker et al. 1978). Coastal upwelling occurs seasonally along the northern coast of the Gulf of Guinea located on the eastern part of the Tropical Atlantic (Binet 1997, Djakouré et al. 2014). In that region, hydrodynamic models were used to simulate the ocean circulation (Djakouré et al., 2014) and fish larval dispersal 10 Koné et al., 2017) but these studies did not include a direct comparison of simulated vs. observed trajectories.

【 In recent years, rapid progress has been made in observation Villas Boas et al. 2019) and numerical modeling (Haza et al. 2012, Liubartseva et al., 2016 , Van Sebille et al. 2018) of the ocean in terms of the complexity of the physical 15 processes considered and the spatial and temporal resolutions over which they are quantified (Döös et al. 2011; Blanke et al. 2012; Choi et al., 2017, D'Asaro et al. 2018). Also, the validation of the ocean velocity fields predicted by circulation models is often realized with temperature and salinity fields, and less often with observed trajectories. Trajectories of surface drifters have been extensively used in a number of Lagrangian transport studies of the ocean surface (Blanke et al., 2001; Döös et al., 2011; Berta et al. 2014; Lacorata et al., 2014; Carlson et al. 2016). When drifter data are lacking or limited, other observation 
data can be used to complement the drifter data. Hence, as a complement to drifters data, trajectories of a few GPS-buoy equipped Fish Aggregating Devices

${ }_{25}$ (FADs) were also used to locate the wreckage of an Air France plane (Drévillon et al. 2013).

FADs are man-made objects that generally consist of a bamboo raft of about 14-6 $\mathrm{m}^{2}$ and hanging nets beneath the raft serving as a subsurface drogue (Bromhead et al., 2003). These nets can go down to $80 \mathrm{~m}$ in the Tropical Atlantic

sо Ocean. FADs are used by fishing vessels to attract tuna and increase fishery productivity (Fonteneau et al. 2013, Maufroy et al., 2017). Several technological devices were added to the rafts including the use of GPS buoys to locate FADs and, more recently, echosounder buoys to monitor the amount of biomass aggregated under them. Baske et al. (2012) and Scott and Lopez (2014) estimated that there are more than 100,000 FADs drifting around the globe. Due to factors such as infrequent deployment of drifters and equatorial divergence (Lumpkin and Pazos, 2007), the drifters are under sampled in the equatorial regions whereas there are many more FADs, particularly in the tropical areas where the purse seine fleets operate. In these regions, it is therefore plausible that FADs could provide complementary data to drifters data. Lagrangian modeling predictability, and impacts of resolution have been topics of intense study using drifters data (Beron-Vera and LaCasce, 2016; Carlson et al., 2016 Dauhajre et al. 2019, Chang et al. 2019). However, the combination of drifters and FADs data have received little attention. Imzilen et al. (2019) showed

45 that oceanographic drifters and FADs drift similarly in the near-surface tropical ocean currents. In tropical waters, there is therefore the possibility of using trajectories of FADs, not only drifters, to corroborate Lagrangian simulations. Bedi et al. (2019) recently investigated that possibility in the Tropical Indian Ocean, mostly.

5o We used an extensive dataset of trajectories of drifters and FADs of the Tropical Atlantic Ocean to assess their trajectories as simulated with a Lagrangian 
model forced by several current products and models. Precisely, the Ichthyop Lagrangian (Lett et al. 2008) was forced by interannual outputs of a CROCO hydrodynamic model configuration of the Tropical Atlantic Ocean, and also by

55 global operational current products derived from the GlobCurrent and OSCAR programs, over the period 1997-2014 for drifters and 2008-2014 for FADs. The objective was to make a comparative analysis of the solutions CROCO-Ichthyop, GlobCurrent-Ichthyop and OSCAR-Ichthyop, using the trajectories of in situ drifters and FADs as references, and also to study the possibility of using FAD data like drifters in Lagrangian studies. The paper is organized as follows. In the next section, we describe the region under study, the observational data (drifters and FADs), the CROCO model, the GlobCurrent and OSCAR ocean current products, the Ichthyop tool, simulation runs and statistical analyses. We then present the results based on the comparison between the observations

65 (both drifters and FADs) and simulated trajectories, and discuss our results in the last section.

\section{Material and methods}

\subsection{Study region}

The region under study is the Tropical Atlantic Ocean located between longitudes $65^{\circ} \mathrm{W}$ and $15^{\circ} \mathrm{E}$, and latitudes $10^{\circ} \mathrm{S}$ and $14^{\circ} \mathrm{N}$ with the Gulf of Guinea as a specific subregion study. Most of the surface currents in that region are zonal and some of them are oriented towards the west side of the basin due to winds blow in that direction (Fig. 1). We have the South Equatorial Current (SEC) and its branches (Bourlès et al. 1999, Lumpkin and Garzoli, 2005) and

75 the North Brazil Current (NBC) along the coast. The North Equatorial Counter Current (NECC) is oriented towards the east of the basin and extends into the Guinea Current (GC), which is the main surface current in the Gulf of Guinea (Richardson and Walsh, 1986, Arnault, 1987). There are also undercurrents in both regions (Bourlès et al. 1999). 


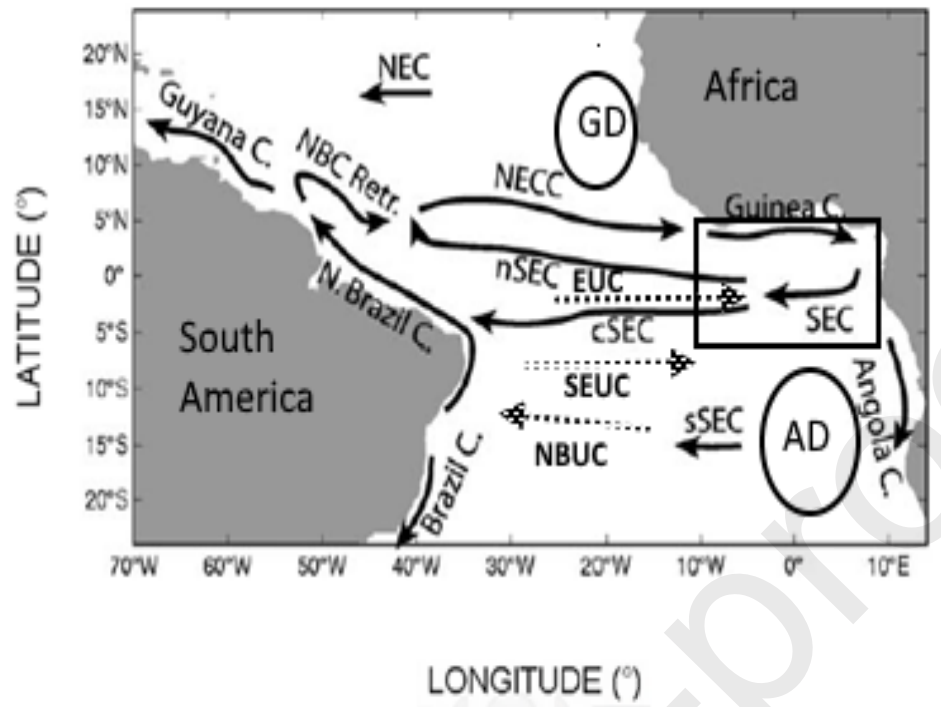

Fig. 1: Schematic of oceanic circulation, the major surface (respectively, subsurface) currents are represented in arrows in solid lines (respectively, dashed lines): North Equatorial CounterCurrent (NECC), Guinea Current (GC), Equatorial UnderCurrent (EUC), Angola Current (AG), northern (nSEC), central (cSEC) and southern (sSEC) branches of the South Equatorial Current (SEC), South Equatorial UnderCurrent (SEUC), North Brazil Currents (NBC) and its retroflection (NBC retr), North Brazil UnderCurrent (NBUC), Brazil Current (BC) and Guyana Current (GC). Rectangle and ellipses represent respectively the Gulf of Guinea region, Guinea Dome (GD) and Angola Dome (AD) (adapted from Lumpkin and Garzoli 2005).

In addition, in the study area seasonal upwelling occurs along the coasts of Côte d'Ivoire and Ghana driving the recruitment of one of the most abundant small pelagic fish, Sardinella aurita (Binet and Marchal, 1993, Djakouré et al. 2014 Koné et al. 2017). Sardinella aurita (S. aurita) plays a key role in the food security of adjacent populations, and into the energy transfer to higher

85 trophic levels (Mbaye et al. 2015). Outputs of circulation models are often used as inputs of biophysical models in order to simulate marine larval dispersal and connectivity (Koné et al. 2017, Swearer et al. 2019). We plan to use this 
approach in a follow up study to study the impact of environmental factors such as temperature, currents and food availability on S. aurita larval survival and recruitment in the northern Gulf of Guinea. The present study is therefore an attempt to compare potential current fields that could be used as forcing factors in a biophysical model.

\subsection{Oceanographic surface drifters}

The surface drifters trajectories (https://data.nodc.noaa.gov/) are gathered 95 by the National Oceanic and Atmospheric Administration (NOAA) through the Global Drifter Program (GDP, Dataset, https://doi.org/10.25921/7ntx-z961) (Laurindo et al. 2017). These drifters are made up of a surface buoy and are drogued at $15 \mathrm{~m}$ depth. The drifters measure properties such as sea surface temperature, currents, air pressure and wind direction and send this information to passing satellites using an ARGOS transmitter (Lumpkin and Pazos, 2007). All older drifters used ARGOS, but in 2015 more than half use Iridium; nearly all drifters are now Iridium with GPS. Their positions are given every six hours (Hansen and Poulain, 1996 recently each hour, Elipot et al. 2016). We keep trajectories of all drifters up to when they arrive close to the CROCO domain border (specifically $3^{\circ}$ of latitude to the southern or northern -open- borders, the eastern and western borders of the domain being mostly closed, coastal, borders). The data obtained between 1997 and 2014 comprise 793 drogued drifters (summing to 339 drifter-years) in our study regions.

\subsection{Fish Aggregating Devices (FADs)}

Fish Aggregating Devices (FADs) are rectangular bamboo rafts with pieces of purse seine nets attached below them in order to attract fish and facilitate their catch (Franco et al. 2009). Positions of the GPS-buoys attached to drifting FADs are given through a collaborative agreement between the Institut de Recherche pour le Développement (IRD) and the French frozen tuna producers 
organization ORTHONGEL. The methodology to obtain and process FAD trajectories are detailed by Maufroy et al. (2015). We used the trajectories of 6,088 drifting FADs in our study region over the period 2008-2014 (summing to 818 FAD-years) based on the same criteria as drifters. It is worth noting that FADs originate mostly from the eastern part of the domain (Fig. A.3b), contrarily to drifters which have a more uniform spatial distribution of their release locations (Fig. A.3a). On average, the lifespan of FADs at sea (40 days; Maufroy et al. (2015)) has been reported to be much shorter than the lifetime of drifters (450 days; Lumpkin et al. (2012)). The sampling periodicity of FADs position varies from 15 min to 2 days but here we used 6 hours for FADs periodicity, like for the drifters.

\subsection{OSCAR product}

OSCAR is a project of the NASA Physical Oceanography Data Center (http://podaac.jpl.nasa.gov). The main objective is to improve the generation of surface currents from oceanic wind fields, and in so doing, the understanding of the mechanisms underlying the energy transfers between the atmosphere and the ocean through the layer planetary limit. This satellite-based product is a computation of global ocean currents based on satellite SSH, scatterometer winds, and both Advanced Very High Resolution Radiometer (AVHRR) and in situ sea surface temperatures (Bonjean and Lagerloef, 2002). Velocities are calculated using quasilinear equations of motion by combining geostrophy, Ekman and Stommel shear dynamics formulations and a complementary term from surface buoyancy gradient (Bonjean and Lagerloef, 2002) directly estimated from sea-surface height, surface wind speed, and sea-surface temperature. The data is on a grid of $\frac{1}{3}^{\circ}$ spatial resolution and with a time resolution of 5 days.

\subsection{GlobCurrent product}

The GlobCurrent product is funded by the European Space Agency. The objective is to provide ocean surface current fields collocated with the sea surface 
temperature field (Johannessen et al. 2016) from multi-satellite altimetry data. GlobCurrent is provided at a $\frac{1}{4}^{\circ}$ spatial resolution and with a time resolution of 1453 hours or 1 day (http://www.globcurrent.org/). This product is obtained by combining the geostrophic currents and Ekman currents (at surface and $15 \mathrm{~m}$ depth). The GlobCurrent geostrophic currents are based on Sea Level Anomalies (SLA) from satellite altimetry and a global Mean Dynamic Topography (MDT) field (Rio et al., 2014). The part of Ekman current in the GlobCurrent product are provided by the Ekman model (Rio et al.,2014) using drogued surface drifter data, Argo floats and near surface winds.

\subsection{CROCO hydrodynamic model configuration}

The hydrodynamical simulation was performed using the new Coastal and Regional Ocean Community model (CROCO) built upon the ROMS-AGRIF model (Debreu et al. 2012). It is a three-dimensional model based on the hydrostatic, incompressibility and Boussinesq hypotheses for solving the primitive equations and also the free surface (Shchepetkin and McWilliams, 2005). The model domain spans $65.2^{\circ} \mathrm{W}-15^{\circ} \mathrm{E}$ and $10^{\circ} S-14^{\circ} \mathrm{N}$ for the parent grid with a horizontal resolution of $\frac{1}{5}^{\circ}$, and the nested high resolution child grid $\frac{1}{15}^{\circ}$ spans $12.33^{\circ} \mathrm{W}-11.73^{\circ} \mathrm{E}$ and $3.98^{\circ} \mathrm{S}-8.05^{\circ} \mathrm{N}$. The vertical levels (45 levels) of the CROCO grid are discretized according to a sigma coordinate system allowing to increase the vertical resolution near the surface and/or the bottom. On the surface, the model is forced with interannual winds (1980-2015) derived from atmospheric reanalysis forcings of ERA-Interim produced by the European Centre for Medium-Range Weather Forecasts (ECMWF) (Dee et al. 2011). The model topography was built using GEBCO 2014 (General Bathymetric Chart of the Oceans (http://www.gebco.net) data. The initial and boundary conditions (heat, fresh water fluxes and currents) for the hydrodynamical model are derived from the outputs of the Simple Ocean Data Assimilation (SODA) version 3.3.1. The model has three open borders (North, South and West) and a closed border (East). We allowed a spin up time of 10 years 
until the model reaches an equilibrium state. The model was run from 19802015 and the outputs were saved every 2 days. Here, the mean annual zonal and meridional velocity $\left(\mathrm{m} \mathrm{s}^{-1}\right)$ of the CROCO model are evaluated against the ocean current observations product from the Global Drifter Center of the NOAA (www.aoml.noaa.gov/phod/dac/dacdata.html) and both altimetry current product (OSCAR and GlobCurrent) over the periods corresponding to our drifter (1997-2014) and FAD (2008-2014) data.

\subsection{Ichthyop Lagrangian model}

The drifter and FAD trajectories were simulated by the Lagrangian model Ichthyop (Lett et al. 2008). Ichthyop is a tool developed in Java that allows to simulate the Lagrangian transport of particles using current fields produced by hydrodynamic models such as CROCO or surface current products such as OSCAR or GlobCurrent, for applications in physical oceanography and in marine ecology. Here drifters and FADs were assumed to drift like discrete particles without mass. Statistical analyses of Lagrangian data from the ocean can be grouped into studies involving single particles and those with pairs or groups of particles (LaCasce, 2008). In the present application, one particle was released at the observed drifters or FAD initial location. The displacement of each particle was given by the sum of an advective and of a dispersive components (Peliz et al. 2007). For simulations with CROCO currents, the particle is released at $15 \mathrm{~m}$ depth. Particle locations were updated at each time step using the Runge-Kutta 4 scheme and saved every six hours, in accordance to the recorded frequencies of the drifters and FADs positions.

\subsection{Sensitivity analysis}

We performed a sensitivity analysis to some of the model choices. For drifters data, we tested simulations where particles were reset every 10 days at the observed locations and also with the release of particles around (within a distance 
of $50 \mathrm{~km}$ or $200 \mathrm{~km}$ ) the drifters initial locations. In addition, for the GlobCur-

FADs, we also simulated clouds of 1,000 released particles instead of only one particle.

\section{Statistical analysis}

\subsection{Velocities RMSE}

205 ulated particles (e.g. Hart-Davis et al., 2018) we used the average velocity error or RMSE (Root Mean Square Error) given by:

$$
R M S E=\sqrt{\sum \frac{\left(V_{\text {real }}-V_{\text {virtual }}\right)^{2}}{N}}
$$

where $V_{\text {virtual }}$ is the simulated particles velocities, $V_{\text {real }}$ the drifter (or FAD) velocities and $\mathrm{N}$ the number of drifters (or FADs). We also compared the overall distribution of velocities for drifters (or FADs) and particles.

\subsection{Separation distance}

The separation distance or error distance measures the separation of two particles or, equivalently, the propagation of a cloud of passive tracers. This index was used here to obtain the evolution of the distance between the observation (drifter or FAD) and the simulation (particle) as a function of time. The separation distance is given by:

$$
D(t)=\sqrt{\left(x_{p}(t)-x_{o}(t)\right)^{2}+\left(y_{p}(t)-y_{o}(t)\right)^{2}}
$$

where $(\mathrm{x}, \mathrm{y})$ are the geographic coordinates in $2 \mathrm{D}$ at time $\mathrm{t}$ and the indices $\mathrm{p}$ and $\mathrm{o}$ refer to the simulated particle and the observed drifters or FADs, respectively. 


\subsection{Absolute dispersion}

The absolute dispersion (Taylor, 1921) is defined as the distance to the initial position at each time:

$$
D_{0}(t)=\sqrt{\left(x_{d}(t)-x_{d}\left(t_{0}\right)\right)^{2}+\left(y_{d}(t)-y_{d}\left(t_{0}\right)\right)^{2}}
$$

where $\left(x_{d}(t), y_{d}(t)\right)$ are the positions of a given observed drifter, FAD or simulated particle at time $\mathrm{t}$ and $\left(x_{d}\left(t_{0}\right), y_{d}\left(t_{0}\right)\right)$ its initial position.

\subsection{The "performance" of the model or skill}

The "performance" of the modeled trajectory is given by :

$$
s s(t)=\left\{\begin{array}{l}
1-\frac{s(t)}{n},(s(t) \leq n) \\
0,(s(t)>n)
\end{array}\right.
$$

with $s(t)=\frac{\langle D(t)\rangle}{\left\langle D_{0}(t)\right\rangle}$ where $\langle D(t)\rangle$ is the average of the separation distances, $<D_{0}(t)>$ the average of the lengths of the observed trajectories and $\mathrm{n}$ the tolerance threshold. We set $\mathrm{n}=1$ like in the work of Liu and Weisberg (2011). If $\mathrm{ss}=1$, there is a perfect match between the trajectory of the drifter (or FAD) and the simulated one. In this case, the relative error is $\mathrm{D}(\mathrm{t})=0$. For $\mathrm{ss}=0$, the model is not efficient, the error $\mathrm{D}(\mathrm{t})$ being of the same order as the distance traveled $D_{0}(t)$. This performance index is equivalent to that proposed by Liu and Weisberg (2011). In general, the skill score is particu35 larly useful when the number of drifter trajectories is limited and neither a conventional Eulerian-based velocity nor a Lagrangian based probability density function may be estimated (e.g. Griffa et al. 2007, Ohlmann and Mitarai, 2010). We calculated the mean and standard deviation of skill values (i.e. $\mathrm{ss}(\mathrm{t})$ ) along time since release (i.e. t) among all drifters and FADs. The number of drifters and FADs were of course decreasing along time and that information was therefore also indicated on the figures. 


\section{Results}

\subsection{Comparison of surface currents}

Fig. 2 shows the mean annual zonal velocities for the Tropical Atlantic basin 245 obtained from the drifters data (Fig. 2a), the CROCO model (Fig. 2b), and the OSCAR (Fig. 2c) and GlobCurrent (Fig. 2d) products. The general patterns of the annual mean of the zonal velocities are consistent with those described by Bourlès et al. (1999) and Lumpkin and Garzoli (2005). Two branches of the westward South Equatorial Current (SEC), the northern branch (nSEC) around $2^{\circ} \mathrm{N}$ and the central branch (cSEC) around $2^{\circ} \mathrm{S}$ (Lumpkin and Garzoli 2005) are visible for NOAA's drifters, CROCO model and GlobCurrent product to some extent. In OSCAR, there are patches of westward velocities that are presumably associated with the nSEC and cSEC, but these are not basin-wide westward jets. In the western basin, the westward North Brazilian Current (NBC) is located along the coast between $10^{\circ} \mathrm{N}$ and $4^{\circ} \mathrm{S}$ for NOAA's drifters and CROCO. It is degraded for OSCAR and GlobCurrent. The eastward flowing North Equatorial Counter Current (NECC) situated between $11^{\circ} \mathrm{N}$ and $4^{\circ} \mathrm{N}$ is also visible for NOAA's drifters, CROCO model and GlobCurrent. In the case of OSCAR, the NECC seems to be degraded like for the branches of the SEC. Drifters, CROCO and GlobCurrent show the connection between the NECC and the Guinea Current (GC) in the Gulf of Guinea, which is not visible in the case of OSCAR. Based on these mean annual zonal velocities maps, CROCO currents seem to be better than GlobCurrent and OSCAR currents. Similar results were obtained for FADs (Appendix Fig. A.1) and also for the annual mean of the meridional velocities (Appendix Fig. A.2) where CROCO is again better than GlobCurrent and OSCAR. 


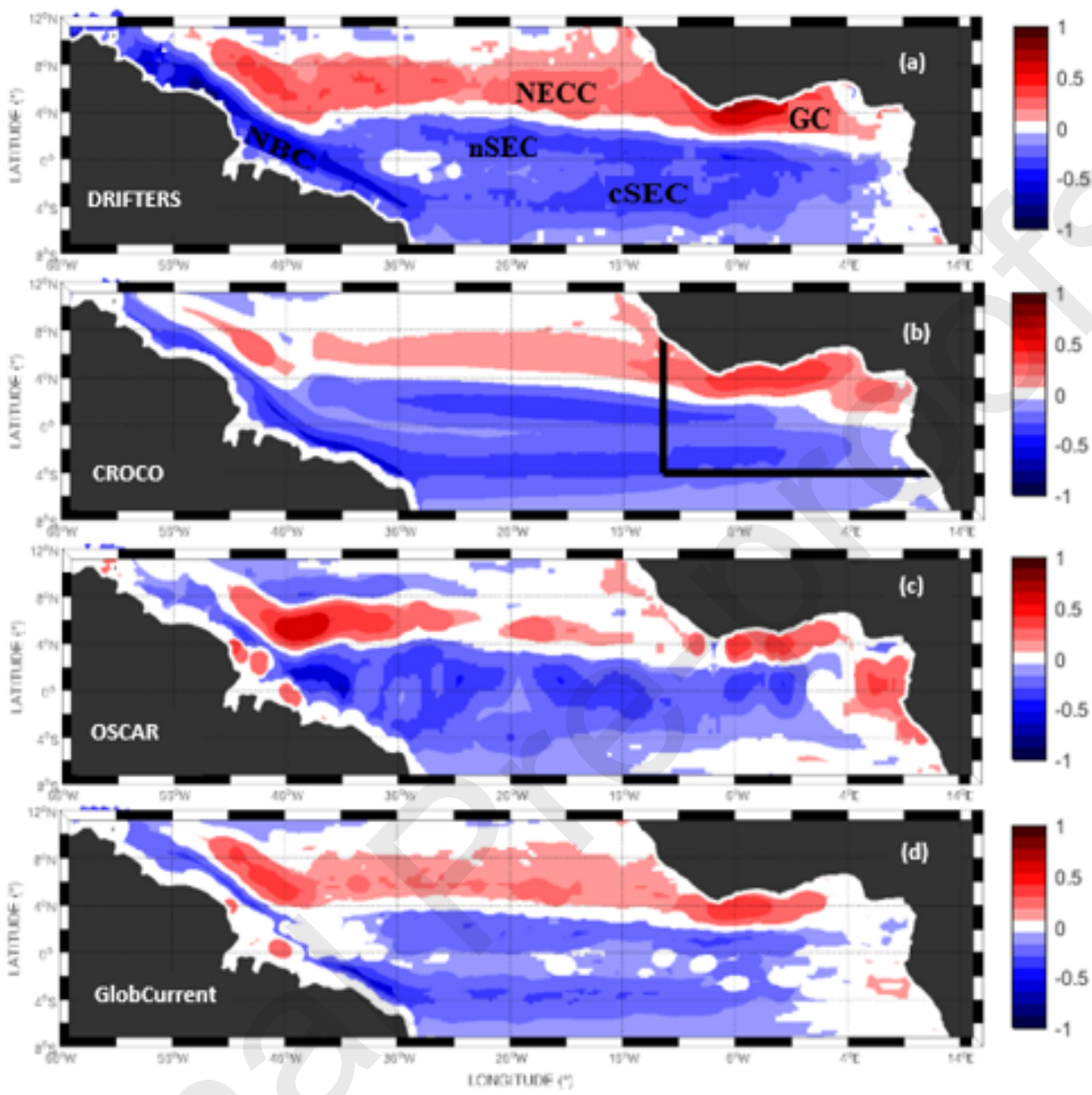

Fig. 2: Mean annual zonal velocity $\left(\mathrm{m} \mathrm{s}^{-1}\right)$ over the period 1997-2014 for (a) NOAA's drifters, (b) CROCO model, (c) OSCAR and (d) GlobCurrent in the Tropical Atlantic. The North Brazil Current (NBC), south and north branches of the South Equatorial Current (sSEC and nSEC), the North Equatorial Counter Current (NECC) and the Guinea Current (GC) are indicated in (a). Solid lines in (b) indicate the boundaries of the Gulf of Guinea. The cell size in (a) is $1^{\circ} \times 1^{\circ}$ and the number of drifters in each cell is shown in Fig 4a. 


\subsection{Comparison of trajectories}

Illustrative pairs of observed and simulated trajectories of drifters were plotted (Fig. 3) and analyzed in terms of dispersion (error and absolute) and speed. Fig. 3a shows the trajectories of the NOAA drifter 116384 (in cyan) and those obtained by Ichthyop forced by CROCO (in black), by OSCAR (in red) and by GlobCurrent (in blue) thereafter referred to as CROCO-Ichthyop (CI), OSCARIchthyop (OI) and GlobCurrent-Ichthyop (GI). The green square represents the initial position. The CI simulation reproduced the path followed by the drifter 116384 well, whereas with the OI and GI simulations the particles were swept away to the West or South of the domain. Fig. 3b shows the trajectory followed by drifter 3136609 along the central branch of the SEC. In this case, the GI simulation reproduced better the drifter's pathway than the CI and OI simulations where the particles were trapped in the northern branch of the SEC. In the same region, the trajectory of drifter 34300 (Fig. 3c) was this time best reproduced by the OI simulation, with particle flowing eastward, contrary to the CI simulation where the particle was flowing westward to the other side of the basin. The particle trajectory obtained with the GI simulation remained trapped by eddies in the release region. In Fig. 3d, all the simulated trajectories followed the same general pathway as the drifter 52860 , whereas none was really good for drifter 33181 (Fig. 3e). Similar results were obtained for FADs where CI, OI or GI simulations provided the best result depending on the considered FAD (Appendix Fig. A.4). 

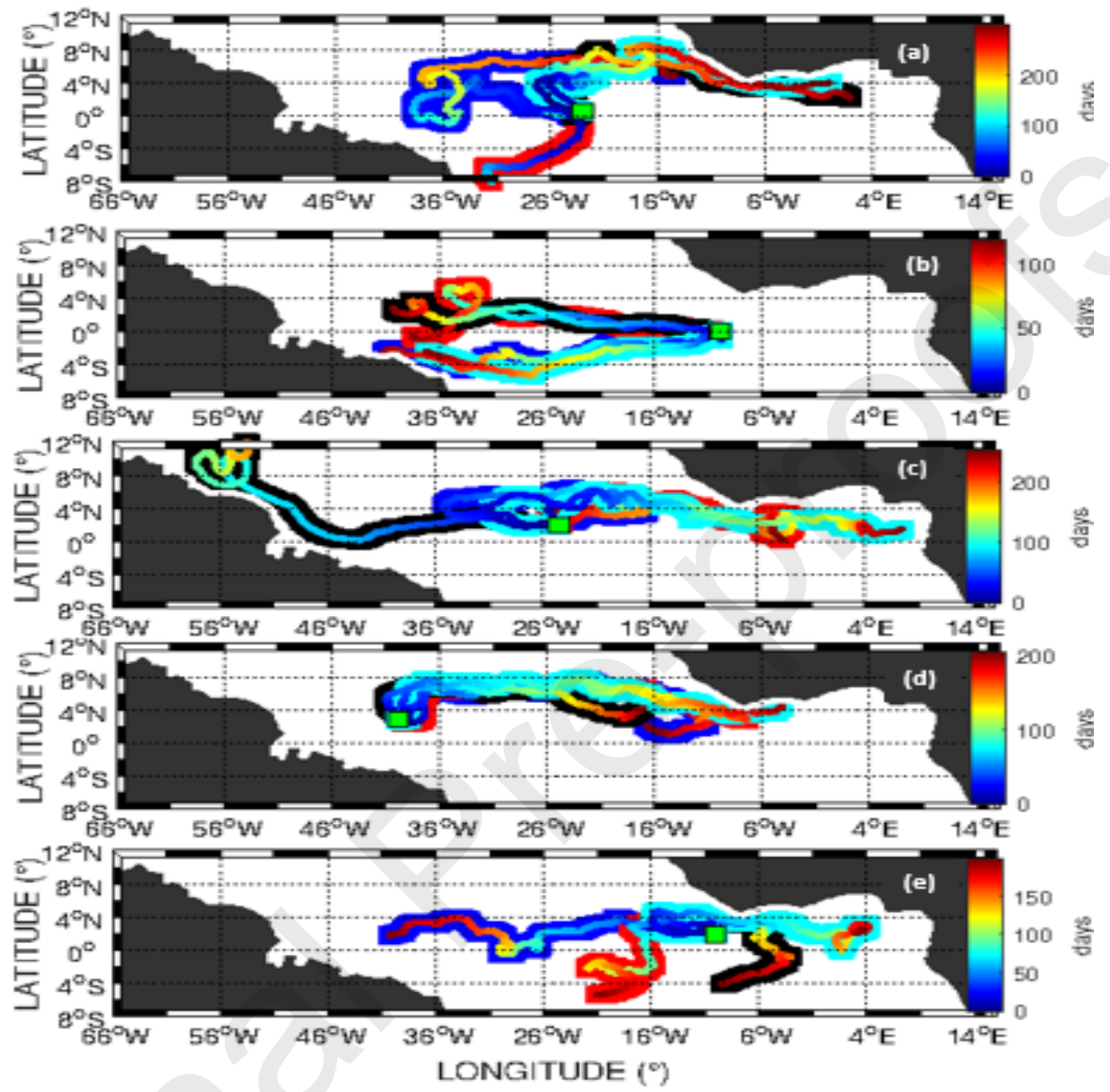

Fig. 3: Trajectories of NOAA drifters (cyan), (a) 116384, (b) 3136609, (c) 34300, (d) 52860 , and (e) 33181 and of particles released at the same location (green square) and time and then transported using the CROCO (black), OSCAR (red) and GlobCurrent (blue) models.

\subsection{Comparison of spatial densities}

In order to get a large-scale spatial view of the differences between simulations and observations, we plotted the density of observed drifters and simulated particles onto a $1^{\circ} \times 1^{\circ}$ cell grid covering the studied domain (Fig. 4). 

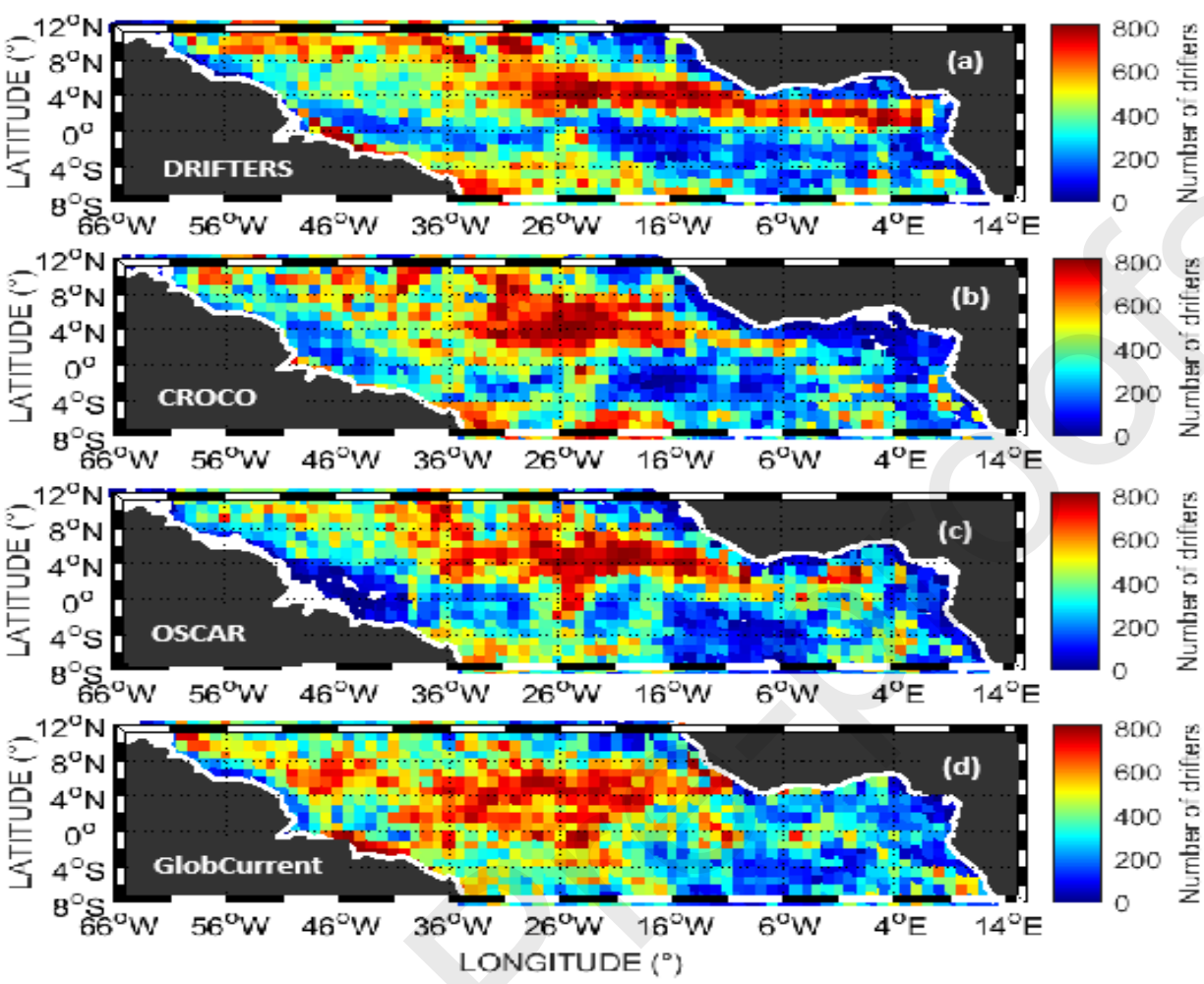

Fig. 4: Densities of (a) observed drifters and simulated particles (using (b) CROCO, (c) OSCAR and (d) GlobCurrent) computed as the average of the number of drifters or simulated particles passing through grid cells of $1^{\circ} \times 1^{\circ}$. Grid cells with zero drifters or simulated particles are shown in white.

The distributions were in an overall good agreement, with most of the drifters and particles being located in the center of the basin around $5^{\circ} \mathrm{N}$ (Fig. 4). However, the particles density was underestimated in the northern Gulf of Guinea in CI, OI and GI simulations compared to drifters density. Along the Brazilian coast south of $0^{\circ} \mathrm{C}$ the GI simulation was more consistent with the observations as there are few particles there with the CI and OI simulations.

The density maps derived from simulations (CI, OI and GI) showed similar patterns and were consistent with those derived from FADs (Fig. 5). Most 
of the particles were concentrated in the eastern part of the domain, whereas the western part displayed the lowest densities (FADs originate mostly in the eastern part of the domain, as shown in Fig. A.3b). However, very few particles reached the western side of the basin above $5^{\circ} \mathrm{N}$, where there were observed FADs.

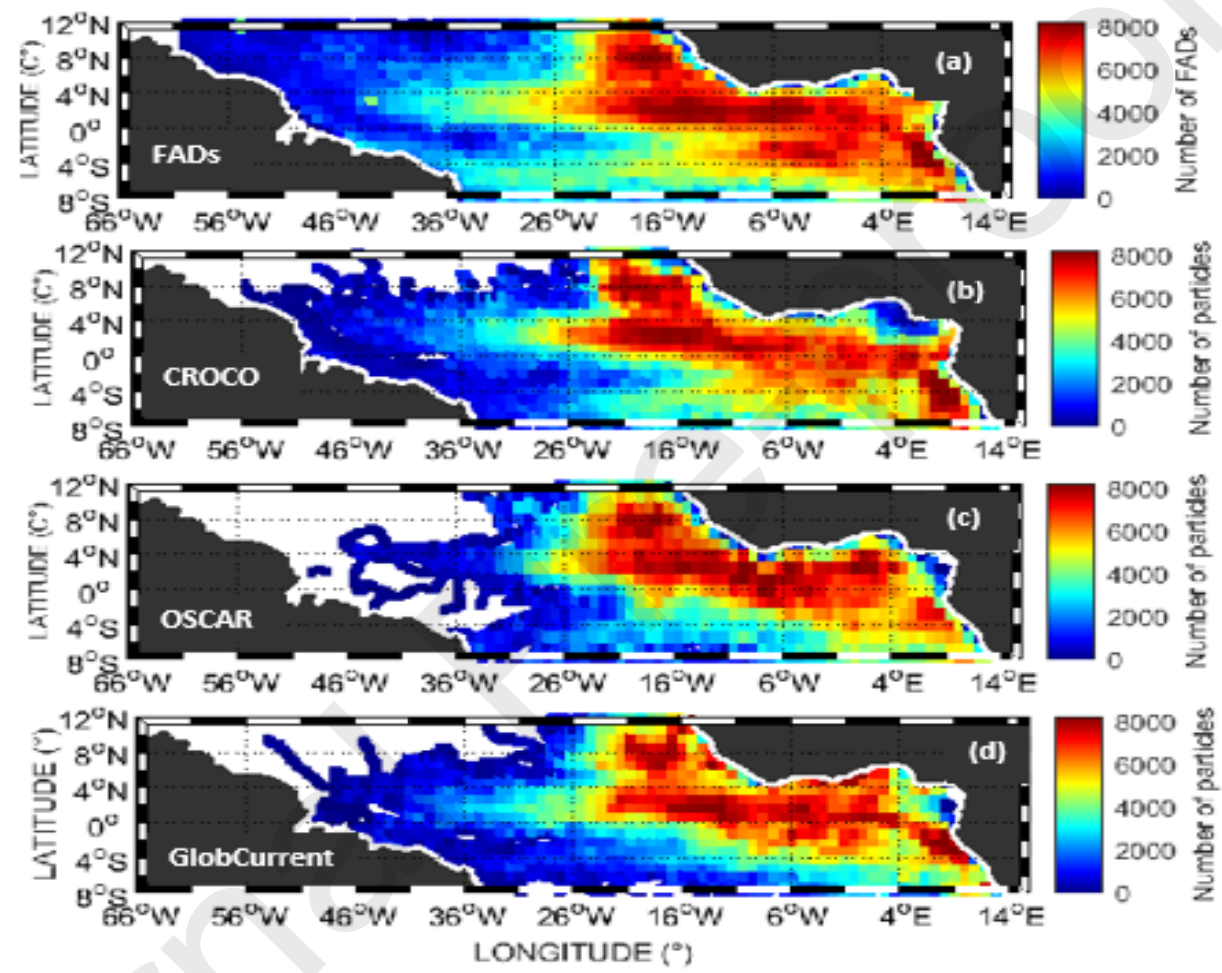

Fig. 5: Same as Fig. 4 but for FADs.

\subsection{Comparison of velocity distributions}

To better understand the differences between observed (drifters or FADs) and simulated velocities, the RMSE was calculated. For drifters in the whole Tropical Atlantic Ocean, we found lower RMSE value for CI $\left(0.39 \mathrm{~m} \mathrm{~s}^{-1}\right)$ than for OI $\left(0.41 \mathrm{~m} \mathrm{~s}^{-1}\right)$ and GI $\left(0.45 \mathrm{~m} \mathrm{~s}^{-1}\right)$. In the Gulf of Guinea, we found again lower RMSE for CI $\left(0.34 \mathrm{~m} \mathrm{~s}^{-1}\right)$ than for OI $\left(0.41 \mathrm{~m} \mathrm{~s}^{-1}\right)$ and GI $\left(0.43 \mathrm{~m} \mathrm{~s}^{-1}\right)$. 
For FADs in the Tropical Atlantic, RMSE values for CI $\left(0.58 \mathrm{~m} \mathrm{~s}^{-1}\right)$ was lower than for OI $\left(0.62 \mathrm{~m} \mathrm{~s}^{-1}\right)$ and GI $\left(0.67 \mathrm{~m} \mathrm{~s}^{-1}\right)$ in the same region. In the Gulf of Guinea, the RMSE of CI $\left(0.36 \mathrm{~m} \mathrm{~s}^{-1}\right)$ is lower than for OI $\left(0.39 \mathrm{~m} \mathrm{~s}^{-1}\right)$ and 315 GI $\left(0.41 \mathrm{~m} \mathrm{~s}^{-1}\right)$.

The mean speed of drifters in the Tropical Atlantic domain was $0.33 \mathrm{~m} \mathrm{~s}^{-1}$, a value significantly higher than obtained with the simulations $(0.26,0.24$, and $0.21 \mathrm{~m} \mathrm{~s}^{-1}$ for GI, OI, and CI, respectively; Table 1). We found the same trend in the Gulf of Guinea (Table 1). Lower mean speeds of simulated particles are in agreement with lower absolute dispersion values obtained for particles than for drifters (Appendix Fig. A.11). The mean speed of FADs $\left(0.26 \mathrm{~m} \mathrm{~s}^{-1}\right)$ was lower than the drifters. Again, in the simulations lower values were obtained $\left(0.21 \mathrm{~m} \mathrm{~s}^{-1}\right.$ for CI and OI and $0.20 \mathrm{~m} \mathrm{~s}^{-1}$ for GI; Table 2), in agreement with the results of absolute dispersion (Appendix Fig. A.12). Results were similar in the Gulf of Guinea (Table 2).

\begin{tabular}{|c|lllr|}
\hline \multirow{2}{*}{ Regions } & \multicolumn{4}{|c|}{ Drifters } \\
\cline { 2 - 5 } & Drifters $\left(m s^{-1}\right)$ & OI $\left(m s^{-1}\right)$ & GI $\left(m s^{-1}\right)$ & CI $\left(m^{-1}\right)$ \\
\hline TA & $0.33 \pm 0.08$ & $0.24 \pm 0.07$ & $0.26 \pm 0.07$ & $0.21 \pm 0.07$ \\
GG & $0.36 \pm 0.05$ & $0.27 \pm 0.06$ & $0.24 \pm 0.04$ & $0.23 \pm 0.04$ \\
\hline
\end{tabular}

Table 1: Mean speed and standard deviation of observed drifters and simulated particles in the whole (Tropical Atlantic, TA) and focus (Gulf of Guinea, GG) regions using using CROCO (CI), OSCAR (OI) or GlobCurrent (GI).

\begin{tabular}{|c|lccc|}
\hline \multirow{2}{*}{ Regions } & \multicolumn{4}{|c|}{ FADs } \\
\cline { 2 - 5 } & FADs $\left(m s^{-1}\right)$ & OI $\left(m s^{-1}\right)$ & GI $\left(m s^{-1}\right)$ & CI $\left(m s^{-1}\right)$ \\
\hline TA & $0.26 \pm 0.09$ & $0.21 \pm 0.05$ & $0.21 \pm 0.05$ & $0.20 \pm 0.04$ \\
GG & $0.28 \pm 0.08$ & $0.24 \pm 0.05$ & $0.22 \pm 0.06$ & $0.22 \pm 0.04$ \\
\hline
\end{tabular}

Table 2: Same as Table 1 but for FADs. 
The drifters (Fig. 6) and FADs (Fig. 7) velocity distributions were comparable with the distributions of particle velocities simulated with CI, OI and GI. However, the simulated velocities distributions were more narrow and shifted towards lower speeds. The lower speed shift was less pronounced with GI for drifters. Similar results were obtained for drifters and FADs velocity fluctuations distributions (Appendix Figs. A.7 and A.8).

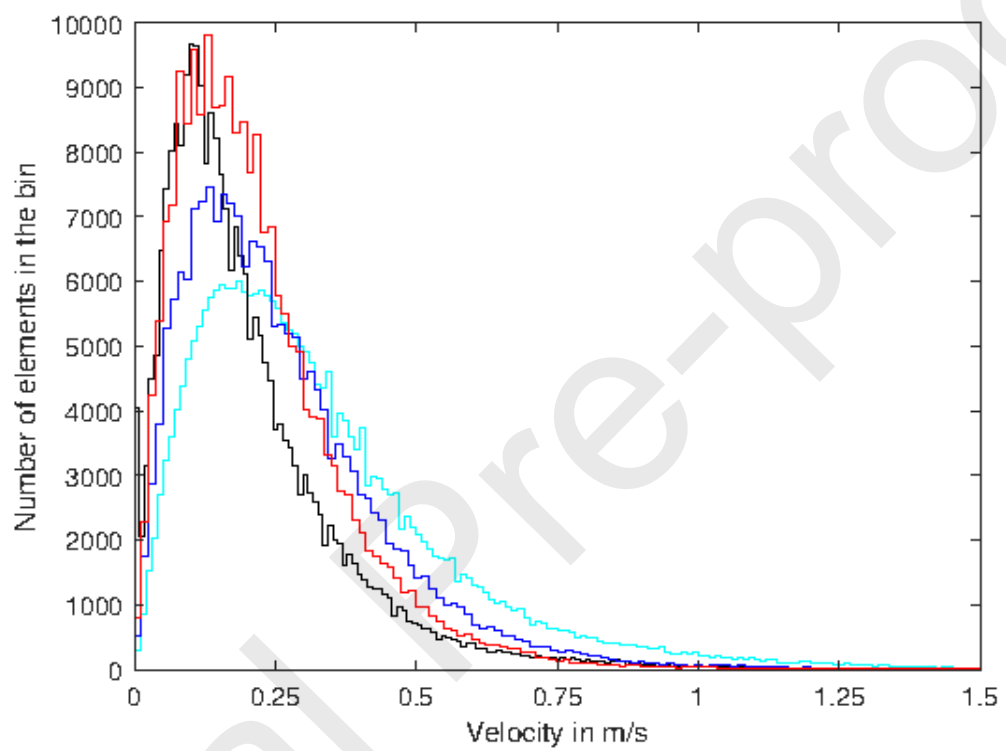

Fig. 6: Velocity distributions of (cyan) observed drifters and simulated particles obtained with (black) CROCO, (red) OSCAR and (blue) GlobCurrent in the tropical Atlantic. 


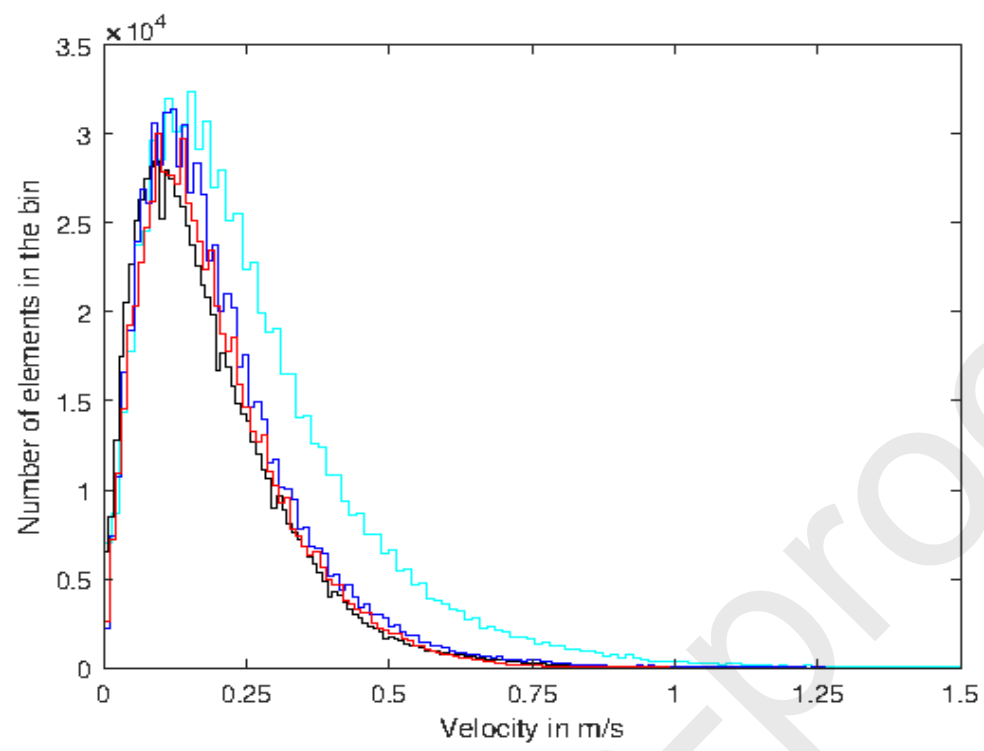

Fig. 7: Same as Fig. 6 but for FADs.

\subsection{Comparison of the models skills}

As a complement to the error or separation distance calculated between simulated particles and drifters (separation distance; Appendix Fig. A.9; in 1 day the mean error distance is $20 \mathrm{~km}, 21 \mathrm{~km}$ and $22 \mathrm{~km}$ for CI, OI and GI, respectively) and FADs (Appendix Fig. A.10; the error is $23 \mathrm{~km}, 25 \mathrm{~km}$ and 27 $\mathrm{km}$ in 1 day with CI, OI and GI, respectively), the skill evaluates the separation distance between drifter or FADs and simulated particles normalized by the distance to the origin. 


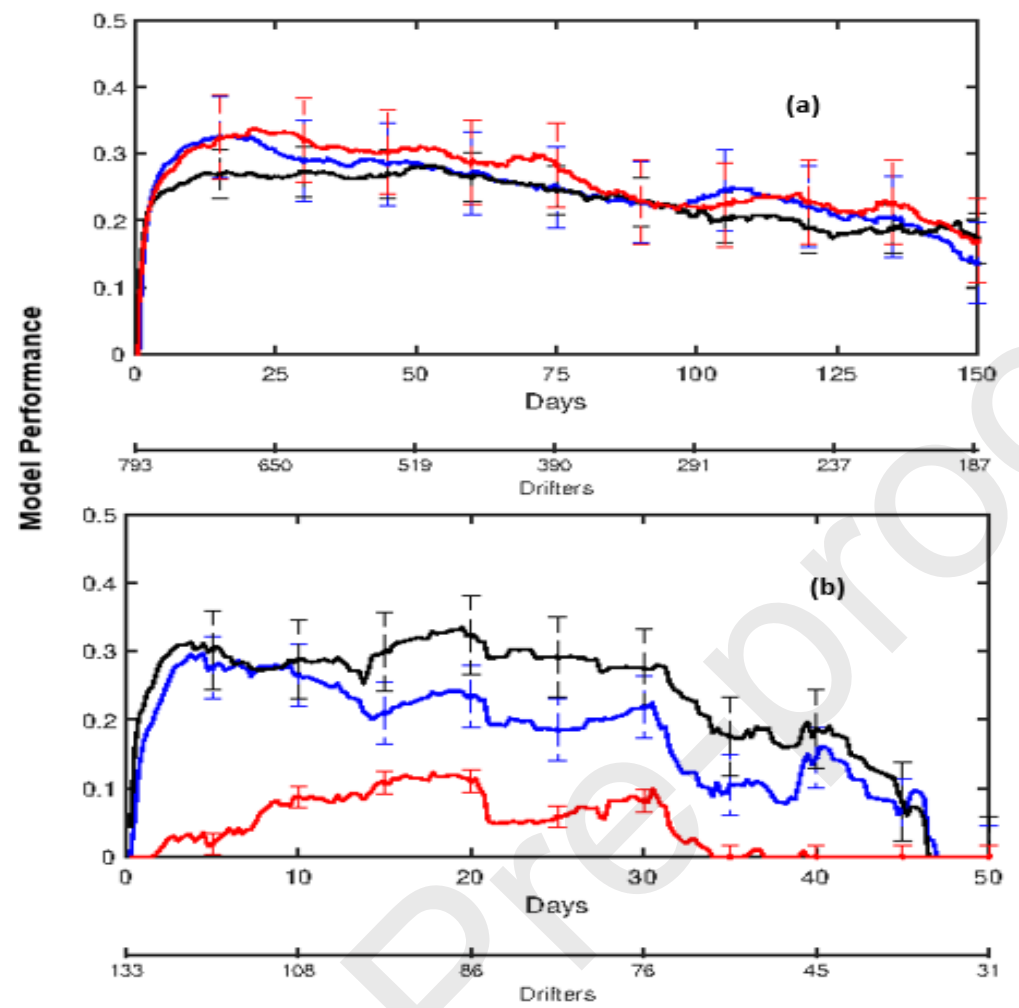

Fig. 8: Mean model performance or skill obtained with (black) CROCO, (red) OSCAR, and (blue) GlobCurrent, (a) for the Tropical Atlantic and (b) the Gulf of Guinea. Note that the number of drifters used for the mean skill calculation (lower scale) decreases with time and that the time periods represented in the two panels are different. The vertical bars represent the standard deviation.

For drifters in the Tropical Atlantic, the mean skill varied much with time, rising sharply in the first days up to 0.4 and then dropping (Fig. 8). The skills obtained with CI, OI and GI were comparable when calculated for the entire Tropical Atlantic dataset (Fig. 8a) but CI performed better in the Gulf of Guinea (Fig. 8b). The same trend was found for FADs (Fig. 9) but the skills were lower than for drifters, reaching a maximum value of 0.1 only. 


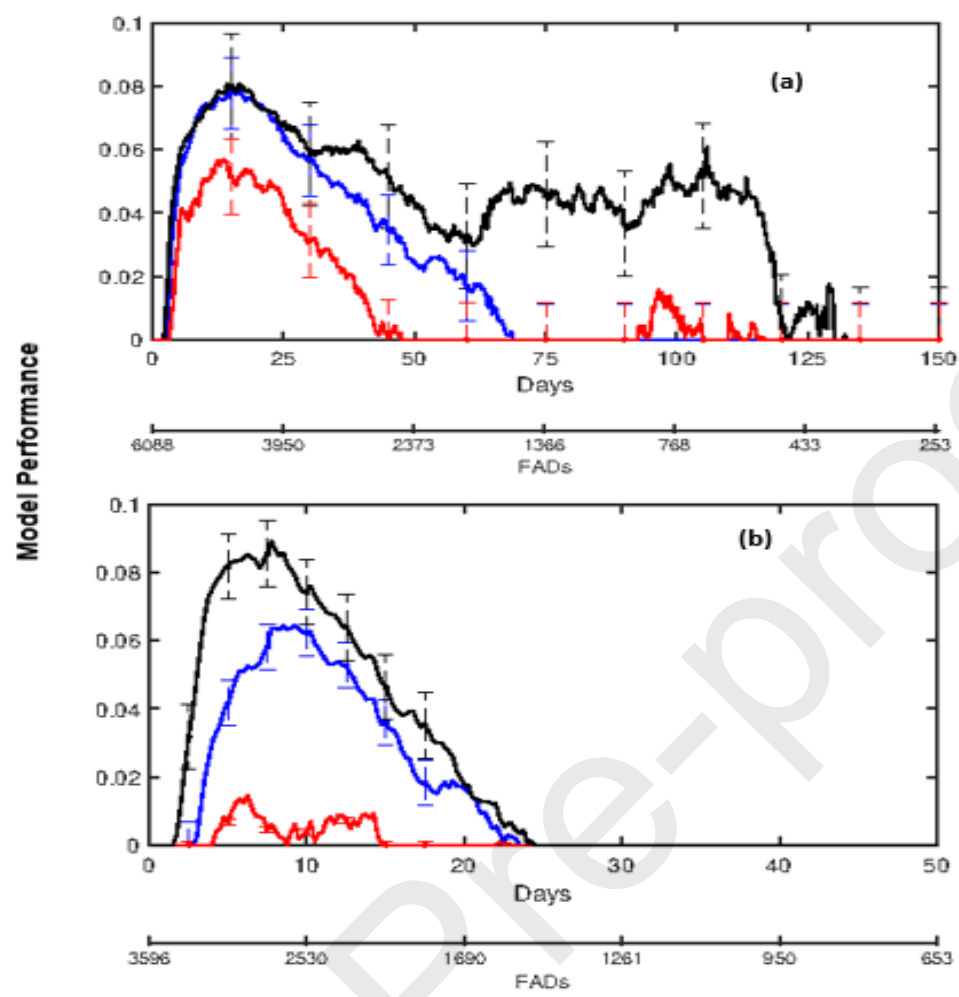

Fig. 9: Same as Fig. 8 but for FADs.

For the drifters dataset, when particles were reset at the observed drifter locations every 10 days, the simulated mean speeds (Appendix Table A.1) were closer to the observed ones and the mean of the model performance over the tenday interval are similar in the Tropical Atlantic (Fig. 10a). The CI simulation still performed better than the others in the Gulf of Guinea (Fig. 10b). In addition, with the others sensitivity analysis (Appendix Figs. A.16, A.17, A.18, A.19, A.20, A.21, A.22 and A.23), we essentially found the same results, showing the robustness of those presented previously. 

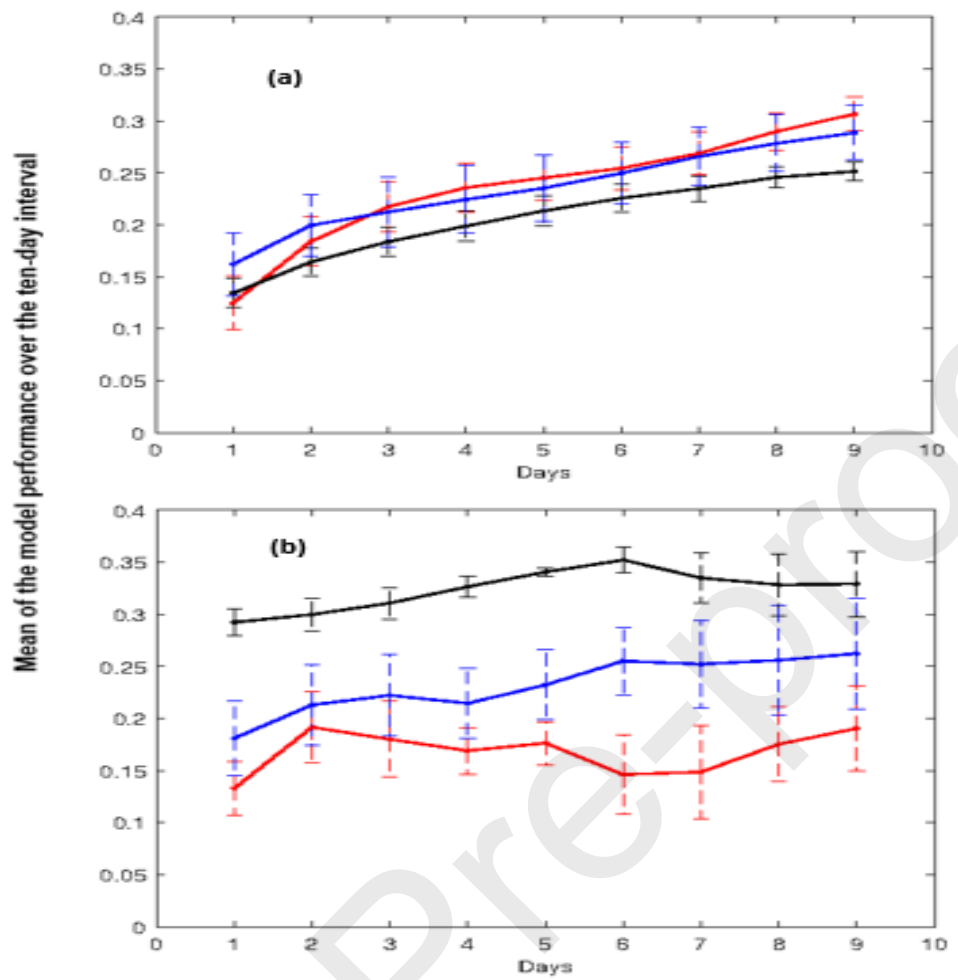

Fig. 10: Mean of the model performance over the ten-day interval when particles are reset every 10 days at the observed drifters locations.

\section{Discussion}

In the Tropical Atlantic Ocean, both satellite products (OSCAR and GlobCurrent) and the CROCO hydrodynamic model used were globally satisfactory to the extent that the main currents of the region were generally represented (Fig. 2, Appendix Fig. A.1). When these currents data were used to force our Lagrangian model in order to simulate trajectories of observed oceanographic drifters and FADs, we found several examples when there was a good agreement between simulations and observations, but also many examples where simulated trajectories were not consistent with observations (Fig. 3, Appendix Fig. A.4). Differences due to vortices, areas of divergence and current variability between 
the forcing products can have significant consequences in terms of simulated trajectories. For example, we found that when the initial positions of drifters or FADs were close to the divergence zone between the three branches of the South Equatorial Current, a small difference in the position of this divergence zone between GlobCurrent, OSCAR and CROCO could lead to dramatically different simulated trajectories. The estimation of the Ekman current may be based on too simple assumptions and parameterization that disfavor the comparison of the simulated particles to the drifters or FADs trajectories (Hart-Davis et al. 2018, Dagestad and Röhrs, 2019). Differences between simulated particles and drifters or FADs trajectories can also be related to current shear, an effect of current velocity varying over the length of the drifters or FADs, and their slip, an effect of wind acting on the surface float (Edwards et al. 2006. Grodsky et al. 2011). Another reason can be attributed to the linear interpolation in space and time employed in the Lagrangian model, although this effect is expected to be small (Qin et al. 2014). It is also possible that the dispersive component included in the model did not adequately account for subgridscale dispersion and contributed to the discrepancy between observations and simulations. Most likely, inconsistencies between simulated and observed patterns are related to the relatively coarse spatial resolution of the currents (CROCO, OSCAR and GlobCurrent) used to simulate the particles (Hart-Davis et al. 2018), leading to unresolved eddy energy known to exist in the northern Gulf of Guinea (Djakouré et al. 2014) and the Tropical Atlantic Ocean (Aguedjou et al. 2019). The accuracy as well as the spatial and temporal resolution of the underlying velocity fields have a big impact on Lagrangian trajectories (Haza et al. 2012, Choi et al., 2017, D'Asaro et al. 2018).

The distribution patterns of FADs and simulated particles (Fig. 5) showed a particularly good agreement. This result may be due to the high number of FADs released in the eastern part of the basin, which appears more favorable to the simulations, whereas the drifters are more evenly released over the whole Tropical Atlantic basin (Appendix Fig. A.3). Phillips et al. (2019) also found 
similar simulated and observed FAD distributions in the Western and Central Pacific Ocean. In the case of drifters and simulated particles, we found differences in some subdomains of the Tropical Atlantic (Fig. 4), in particular in the Gulf of Guinea and along the South American coast. These differences can be attributed to the coarser spatial resolution of the different current used to advect the particles. This is supported by Djakouré et al. (2014) and Aguedjou et al. (2019) who found a considerable number of eddies in the Gulf of Guinea and along the South American coast.

The velocity of simulated particles were overall slightly lower than the velocity of drifters and FADs (Figs. 6 and 7). The Tropical Atlantic is a highly energetic ocean zone with a strong thermal gradient and great variability (Caltabiano et al. 2005; Fratantoni and Richardson, 2006). It drives a lot of mesoscale structures that are not resolved by the satellite products or the hydrodynamic model CROCO at the resolution used, which can reduce the simulated velocity like already noticed by Putman and He (2013) and Hart-Davis et al. (2018). Submesoscale processes, that is, with length scales of $0.1-10 \mathrm{~km}$ (Thomas et al. 2008), are important in the upper ocean (McWilliams, 2008, Klein and Lapeyre, 2009) can contribute to the reduction of simulated speeds. The difference between the OSCAR five-day current and in situ observations currents are related to dynamic processes that are difficult to resolve (e.g., tropical instability waves and high latitude eddies) (Johnson et al. 2007). Meyer et al. (2017) suggested 415 that GlobCurrent-based velocity fields significantly underestimate the directly observed currents due to the temporal averaging of the data in their generation, like for OSCAR (Imzilen et al., 2019). The regularly gridded satellite data (GlobCurrent or OSCAR) are produced using optimal interpolation and merging techniques to fill the gaps between spatially sparse satellite ground tracks. This merging process results in the smoothing of the data in both space and time (Ducet et al. 2000; Meyer et al. 2017) and also the underestimation of the ocean current velocities. The underestimation obtained with CROCO is likely associated with insufficient resolution. McClean et al. (2002) showed that model 
velocities agreed better with those of drifters when the model resolution became higher. CROCO velocities were generally slightly slower than velocities of both satellite derived estimated currents (OSCAR and GlobCurrent). A possible explanation is that velocity was estimated using the straight-line distance from one point to the next. Mesoscale processes better resolved in CROCO might tend to reduce the distance traveled by particles, and thereby their apparent velocity, compared to the Eulerian satellite derived current estimates (Fossette et al. 2012).

The error values obtained for drifters in our work are in the range of the values obtained previously by Barron et al. (2007), Huntley et al. (2010), and Hart-Davis et al. (2018), i.e., 10-25 km after 1 day. The increase in the models skill (Figs. 8 and 9) over the first few days likely reflects the effects of separation scale. Once the separation scale is comparable to the resolution of the velocity field, the separation should decrease as the dominant features responsible for the advection of particles are now resolved, at least in space. The models skill increased like in previous work (Ivichev et al. 2012, De Dominicis et al., 2016.

${ }_{440}$ Sorgente et al. 2016). All skills are comparable in the Tropical Atlantic. This is likely due to the similar spatial resolutions $\left(\frac{1}{5}^{\circ}\right.$ for CROCO, $\frac{1}{4}^{\circ}$ for GlobCurrent and $\frac{1}{3}^{\circ}$ for OSCAR) and in the open ocean, tidal flows and some processes which are not resolved in the currents are very weak and can generally be ignored. This is consistent with Scott et al. (2012) and Liu et al. (2014) who found 445 that altimetry products had similar performances as ocean models in the equatorial Atlantic and in the Gulf of Mexico, respectively. The similar performance of GlobCurrent, OSCAR and CROCO currents may also be related to the fact that they used similar wind data from atmospheric reanalyses (Dagestad and Röhrs, 2019). However, on average, the skill of CROCO-Ichthyop was higher than those of both altimetry products in the Gulf of Guinea. This is likely due to the parent solution of $\mathrm{CROCO}$ which benefited from the increased resolution $\left(\frac{1}{15}^{\circ}\right)$ of the child solution in that region, due to the two-way embedding procedure that we used. Increasing resolution will generaly improve results as shown 
previously (Liu et al., 2014, De Dominicis et al., 2016, Sorgente et al., 2016). et al., 2011). Also, the altimetry products temporal sampling (weekly maps) are not high enough to resolve synoptic variability of the coastal circulation $(\mathrm{He}$ et al., 2004). Monthly climatology of Eddy Kinetic Energy (EKE) assessed from CROCO and GlobCurrent (Fig. A.24a, c) compare well with EKE estimated CAR (Fig. A.24b), with high values obtained along the coast where the Guinea Current flows and also offshore along the northern branch of the SEC for some months (particularly June, July and December). Highest values of EKE are obtained east of coastal capes (Djakouré et al., 2014).

The mean skills obtained with the FADs were smaller than those obtained with drifters, and just above 0 . While drifters drogues are centered at $15 \mathrm{~m}$ below the surface, the FADs subsurface structures can go down to $80 \mathrm{~m}$ in the Tropical Atlantic. These differences in anchoring depth between drifters and FADs locate them in different current layers. Since the currents fields used in the work to force Ichthyop represented the mixed layer $(0-30 \mathrm{~m})$, their drogue structures could explain the small value of skill obtained for FADs. Imzilen et al. (2019) already pointed that drifters moved faster than FADs in the Tropical Atlantic, unlike in the Tropical Indian Ocean. Our results reinforce that view and therefore suggest that in the Tropical Atlantic the FAD dataset may not be structures are such that FADs do not drift like water parcels. Phillips et al. (2019) further suggested that changes in the transmission frequency of FAD locations can contribute to differences between simulated and observed FAD distributions, and hence to model skills.

Outputs of circulation models are often used as inputs of biophysical models in order to simulate marine larval dispersal and connectivity. In the most recent review, Swearer et al. (2019) estimated that more than $20 \%$ of all marine larval 
dispersal models used CROCO (former ROMS) outputs. We believe that it is however useful to compare CROCO outputs to other models or operational

${ }_{485}$ current products like we did here with OSCAR and GlobCurrent in order to assess the skill of Lagrangian simulations, but also to account for variability between current models or products in marine connectivity studies (Hufnagl et al. 2017).

\section{Acknowledgements}

490 This research is supported by the French Institut de Recherche pour le Développement (IRD) and Sorbonne University through the PDIMSC (Programme Doctoral International de Modélisation des Systèmes Complexes). The FAD buoy data were produced by ORTHONGEL and the fishing companies CFTO, SAPMER, and SAUPIQUET. We are grateful to the AOML's drifting 495 buoy group for making their drifter data available and acknowledge the OSCAR and GlobCurrent Project Office for providing the surface current data. We would also like to thank Nicolas Barrier for the plugin of GlobCurrent in Ichthyop, Pierrick Penven for his technical support for the CROCO model implementation, and three anonymous reviewers for their very useful comments. 


\section{Appendix}

\begin{tabular}{|c|lllr|}
\hline \multirow{2}{*}{ Regions } & \multicolumn{4}{|c|}{ Drifters } \\
\cline { 2 - 5 } & Drifters $\left(m s^{-1}\right)$ & OI $\left(m s^{-1}\right)$ & GI $\left(m s^{-1}\right)$ & CI $\left(m s^{-1}\right)$ \\
\hline TA & $0.33 \pm 0.08$ & $0.25 \pm 0.08$ & $0.26 \pm 0.07$ & $0.22 \pm 0.08$ \\
GG & $0.36 \pm 0.05$ & $0.28 \pm 0.06$ & $0.23 \pm 0.05$ & $0.25 \pm 0.04$ \\
\hline
\end{tabular}

Table A.1: Same as Tab. 1 when particles are reset every 10 days at the observed drifters location.

\begin{tabular}{|c|llcc|}
\hline \multirow{2}{*}{ Regions } & \multicolumn{4}{|c|}{ Drifters } \\
\cline { 2 - 5 } & Drifters $\left(m s^{-1}\right)$ & OI $\left(m s^{-1}\right)$ & GI $\left(m s^{-1}\right)$ & CI $\left(m s^{-1}\right)$ \\
\hline TA & $0.33 \pm 0.08$ & $0.20 \pm 0.07$ & $0.21 \pm 0.07$ & $0.19 \pm 0.05$ \\
GG & $0.36 \pm 0.05$ & $0.24 \pm 0.05$ & $0.22 \pm 0.04$ & $0.23 \pm 0.03$ \\
\hline
\end{tabular}

Table A.2: Same as Tab. 1 but using a cloud of 1,000 particles released at the observed drifters initial locations.

\begin{tabular}{|c|lccc|}
\hline \multirow{2}{*}{ Regions } & \multicolumn{4}{|c|}{ FADs } \\
\cline { 2 - 5 } & FADs $\left(m s^{-1}\right)$ & OI $\left(m s^{-1}\right)$ & GI $\left(m s^{-1}\right)$ & CI $\left(m s^{-1}\right)$ \\
\hline TA & $0.26 \pm 0.09$ & $0.18 \pm 0.04$ & $0.20 \pm 0.06$ & $0.18 \pm 0.08$ \\
GG & $0.28 \pm 0.08$ & $0.22 \pm 0.06$ & $0.24 \pm 0.05$ & $0.21 \pm 0.07$ \\
\hline
\end{tabular}

Table A.3: Same as Tab. 1 but using a cloud of 1,000 particles released at the observed FADs initial locations. 


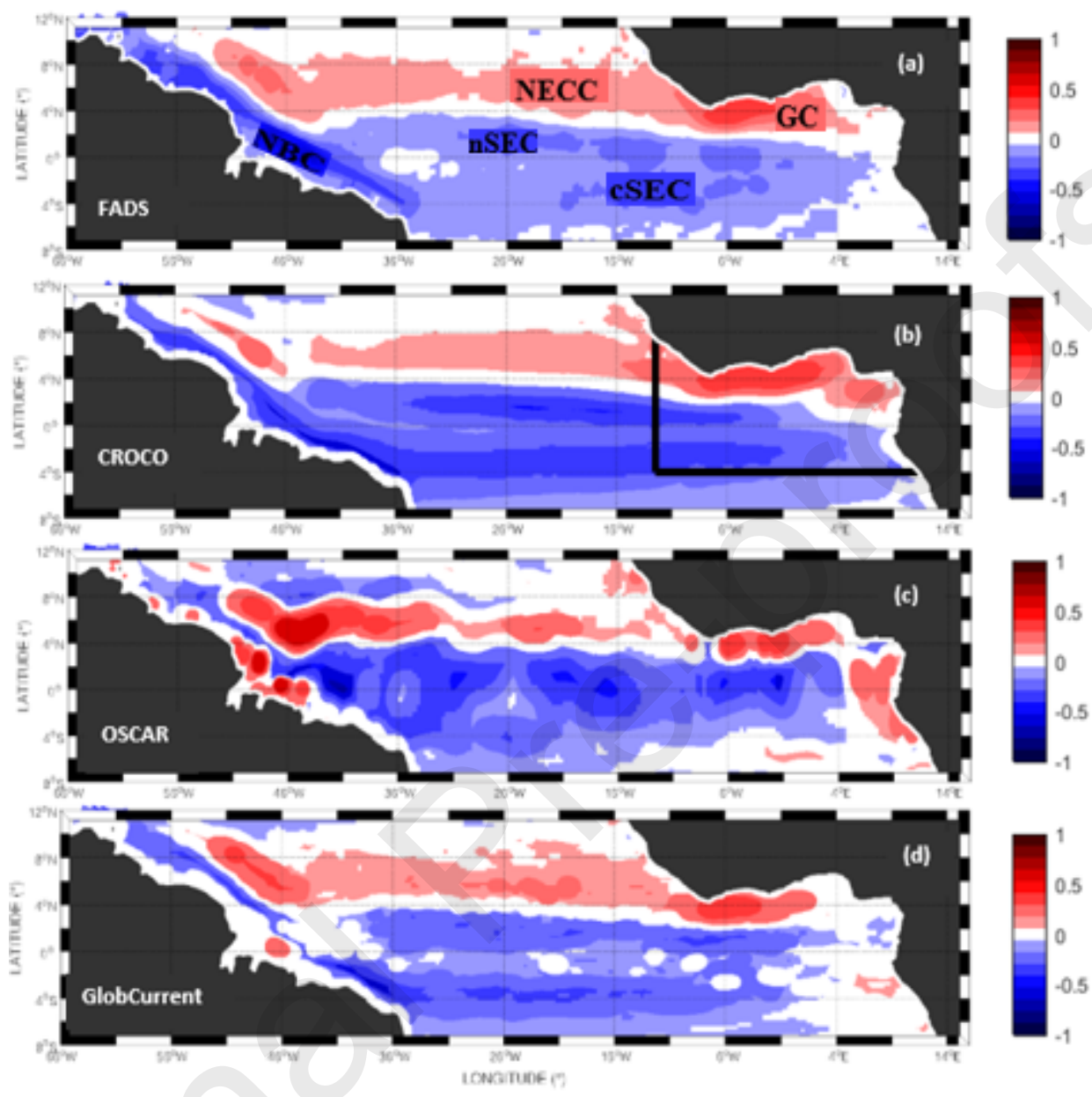

Fig. A.1: Same as Fig. 2 but the mean annual zonal velocity covers the period of FAD data. 


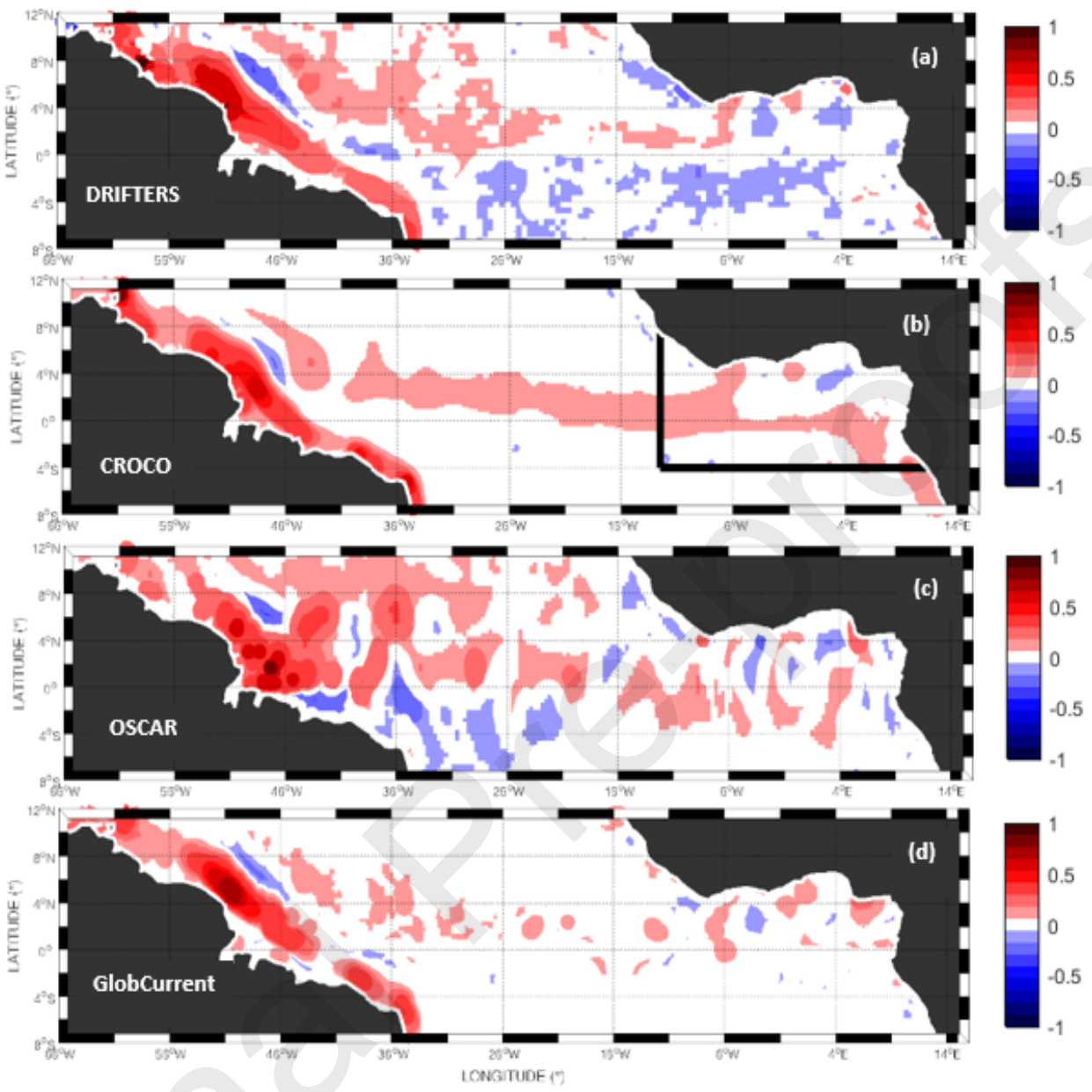

Fig. A.2: Same as Fig. 2 but the mean annual meridional velocity. 


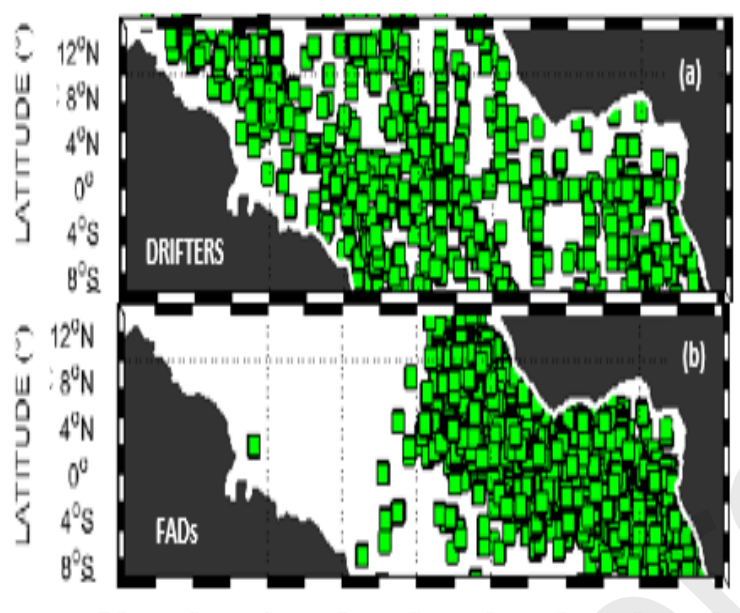

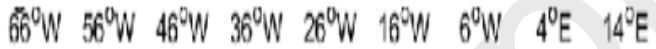

LONGITUDE (")

Fig. A.3: Initial positions of (a) drifters and (b) FADs. 

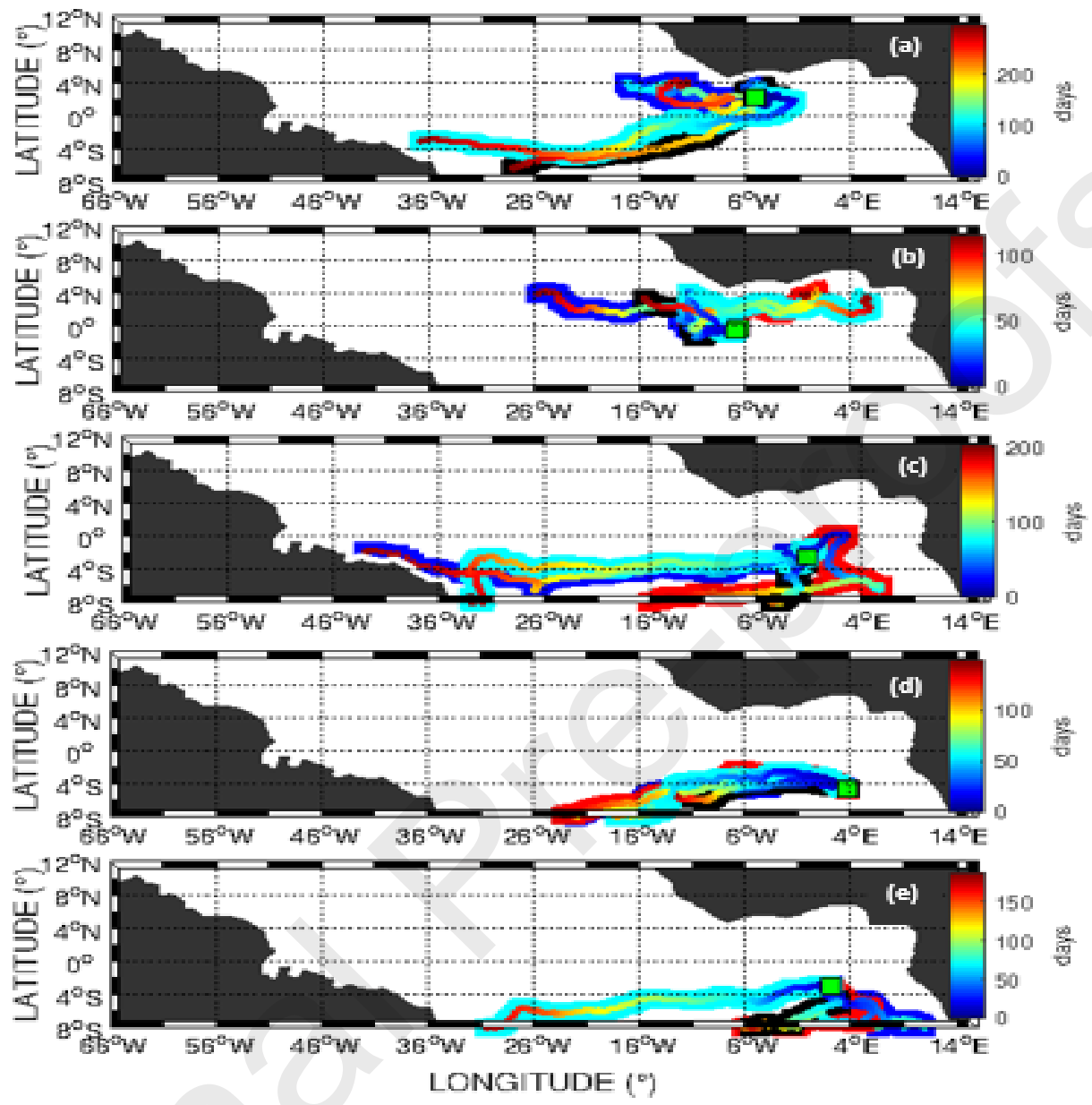

Fig. A.4: Same as Fig. 3 for (a) FAD 9740, (b) FAD 379, (c) FAD 14865, (d) FAD 731 and (e) FAD 14890. 


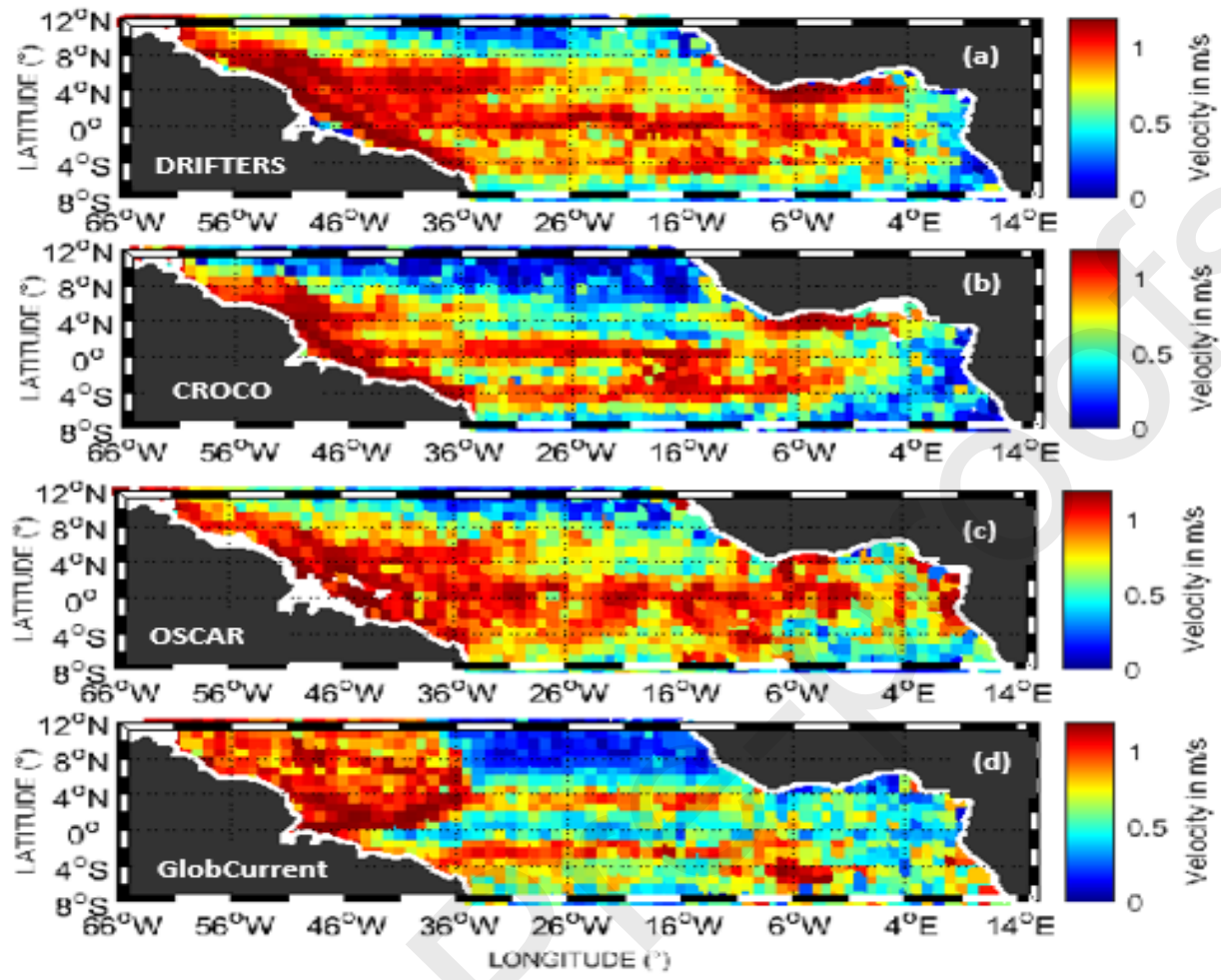

Fig. A.5: Mean velocity of (a) drifters and simulated particles (using (b) CROCO, (c) OSCAR and (d) GlobCurrent) passing through grid cells of $1^{\circ} \times 1^{\circ}$. Grid cells with zero drifters or simulated particles are shown in white. 

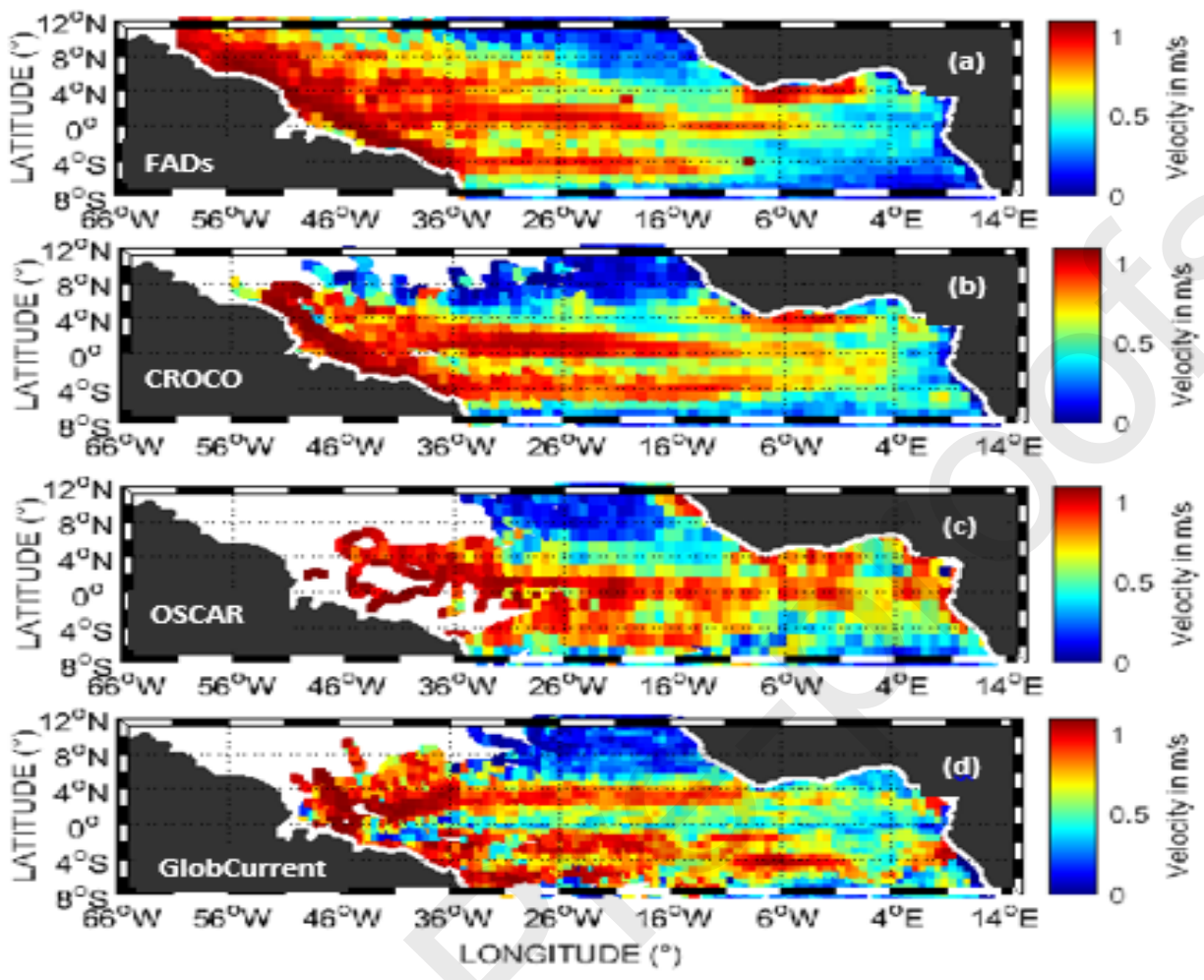

Fig. A.6: Same as Fig. A.5 but for FADs 


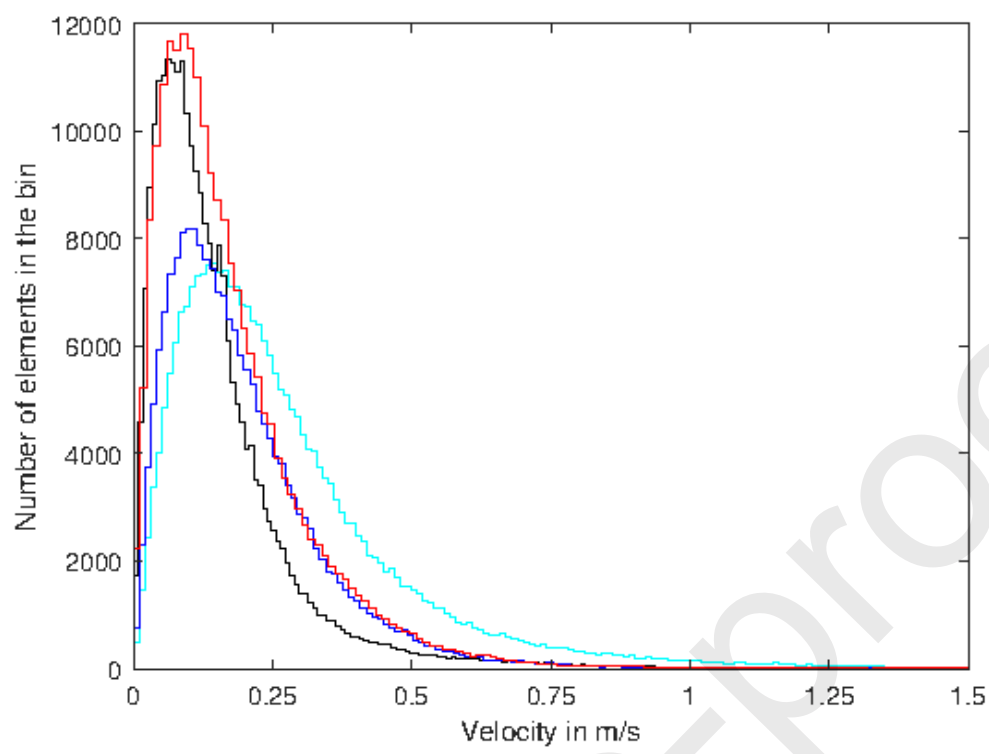

Fig. A.7: Velocity fluctuations distributions were comparable with the distributions of particle velocities simulated with CI, OI and GI. However, the simulated velocities fluctuations distributions were more narrow and shifted towards lower speeds. The lower speed shift was less pronounced with GI for drifters 


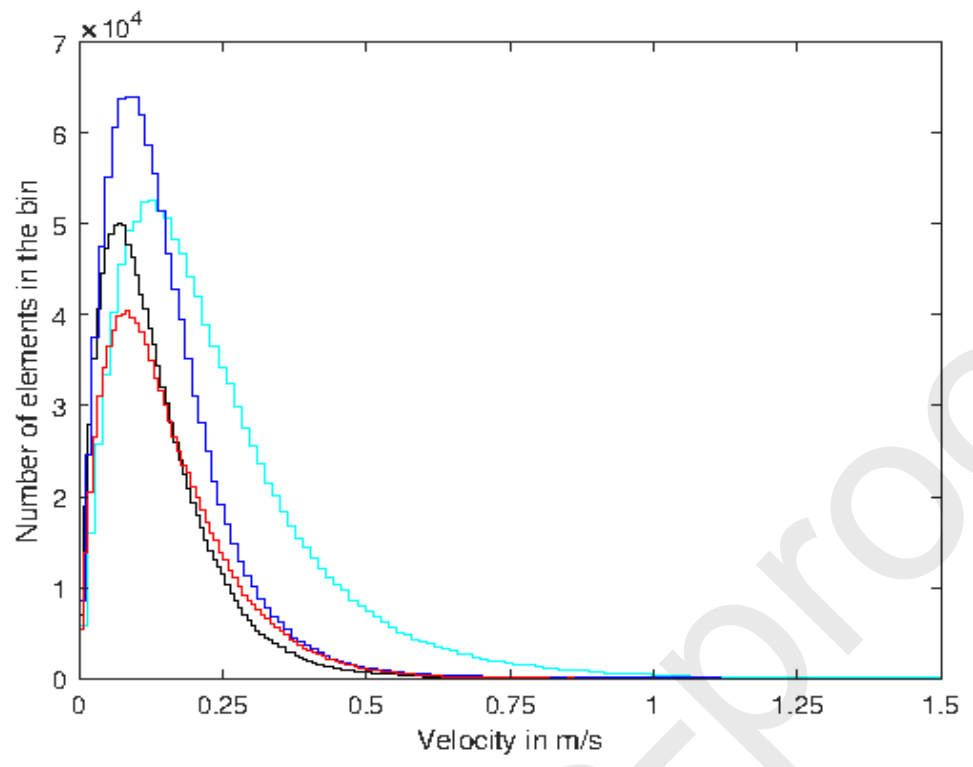

Fig. A.8: Same as Fig. A.7 but for FADs. 


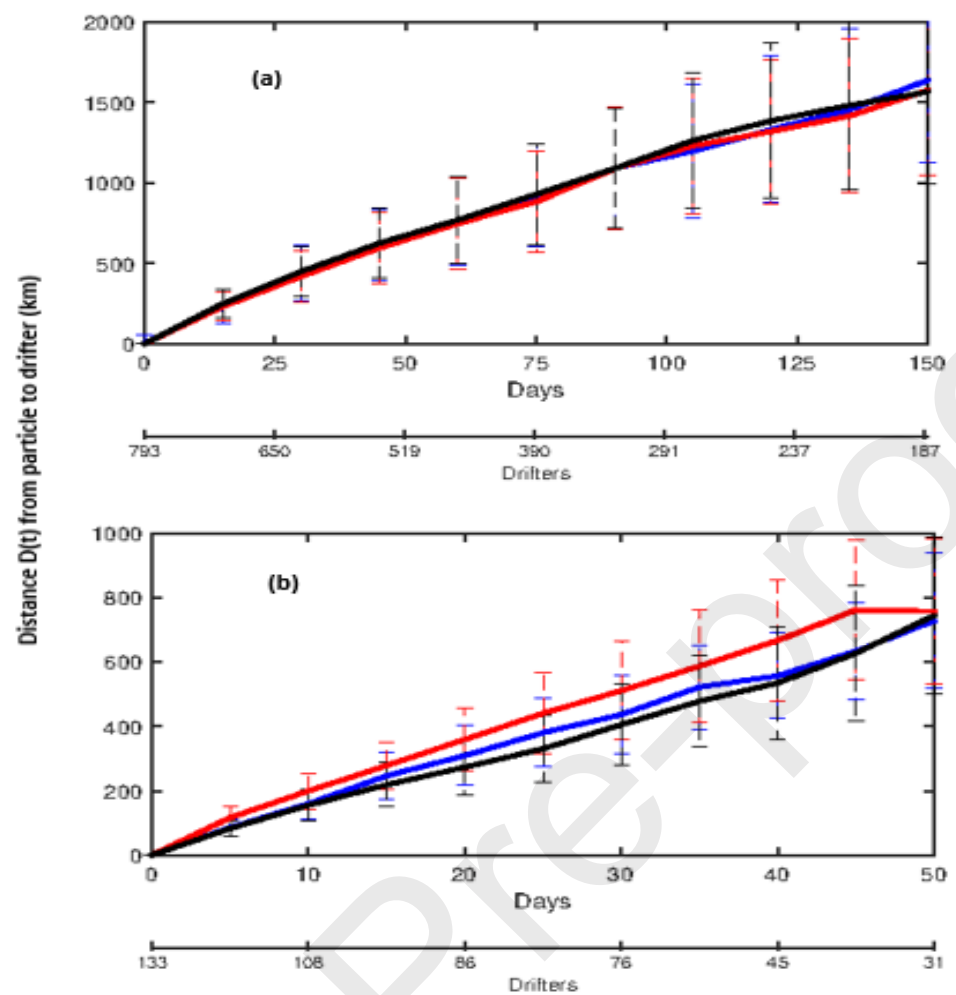

Fig. A.9: Mean separation distance (or model error distance) over time between simulated particles and NOAA drifters obtained with (black) CROCO, (red) OSCAR and (blue) GlobCurrent for (a) the whole Tropical Atlantic and (b) the Gulf of Guinea. 


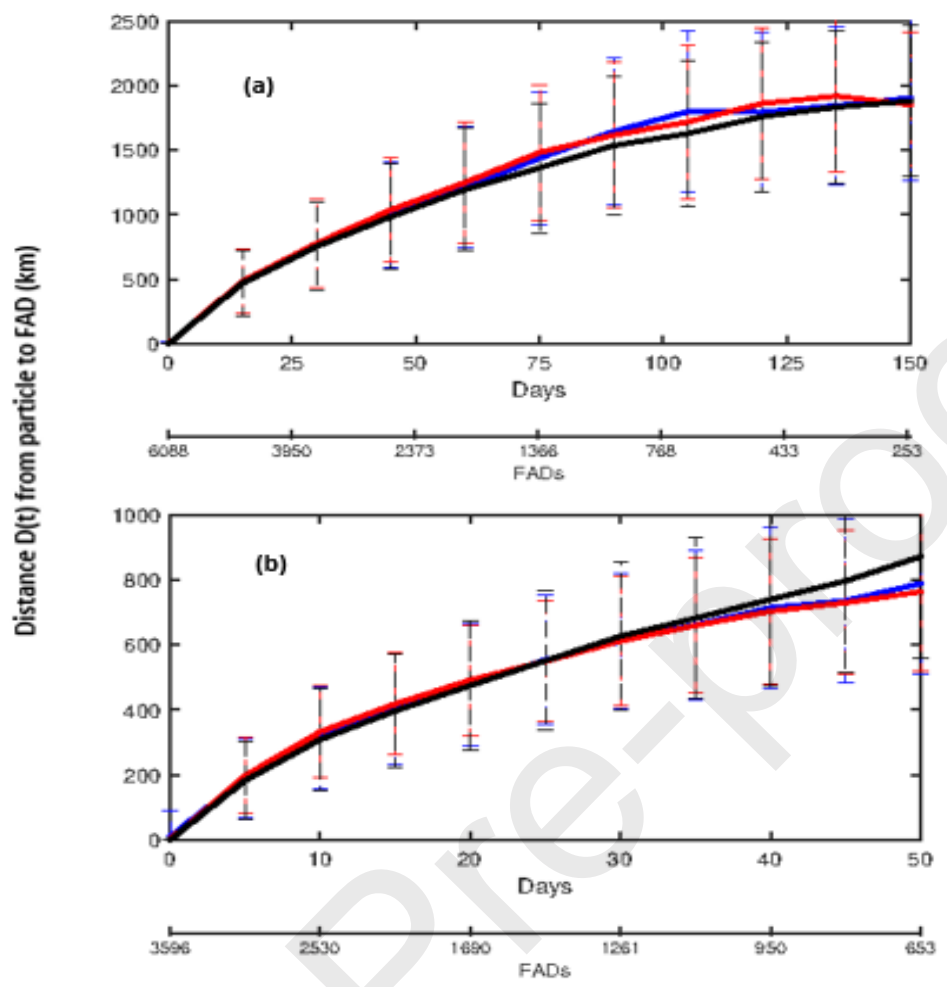

Fig. A.10: Same as Fig. A.9 but for FADs. 


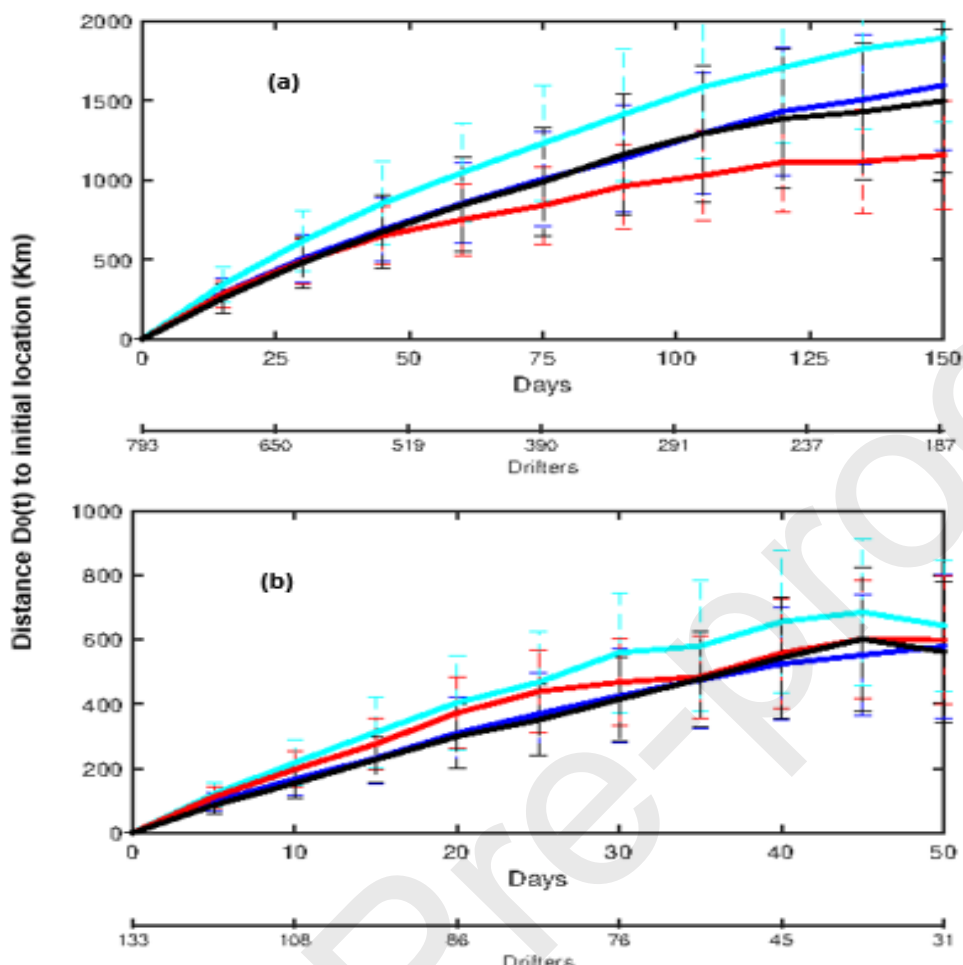

Fig. A.11: Mean absolute dispersion (or distance to release location) over time obtained for (cyan) NOAA drifters and simulated particles with (black) CROCO, (red) OSCAR and (blue) GlobCurrent for (a) the whole Tropical Atlantic (a) and (b) the Gulf of Guinea. 


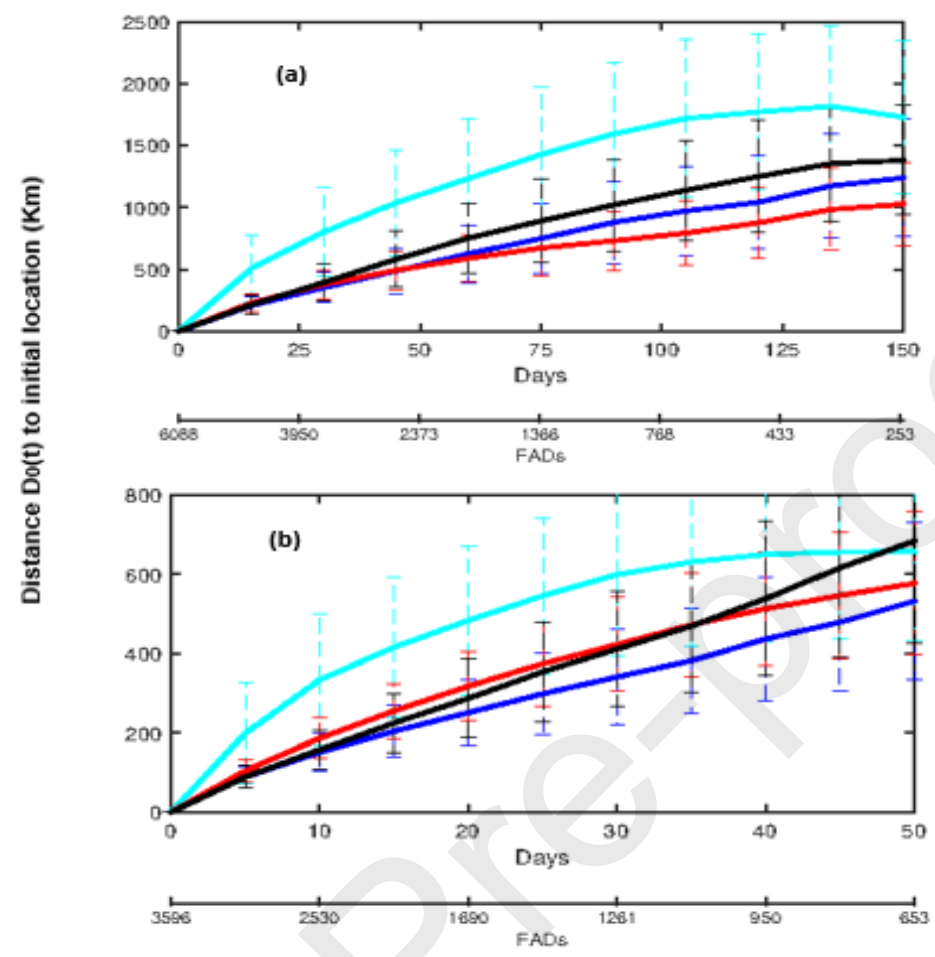

Fig. A.12: Same as Fig. A.11 but for FADs. 


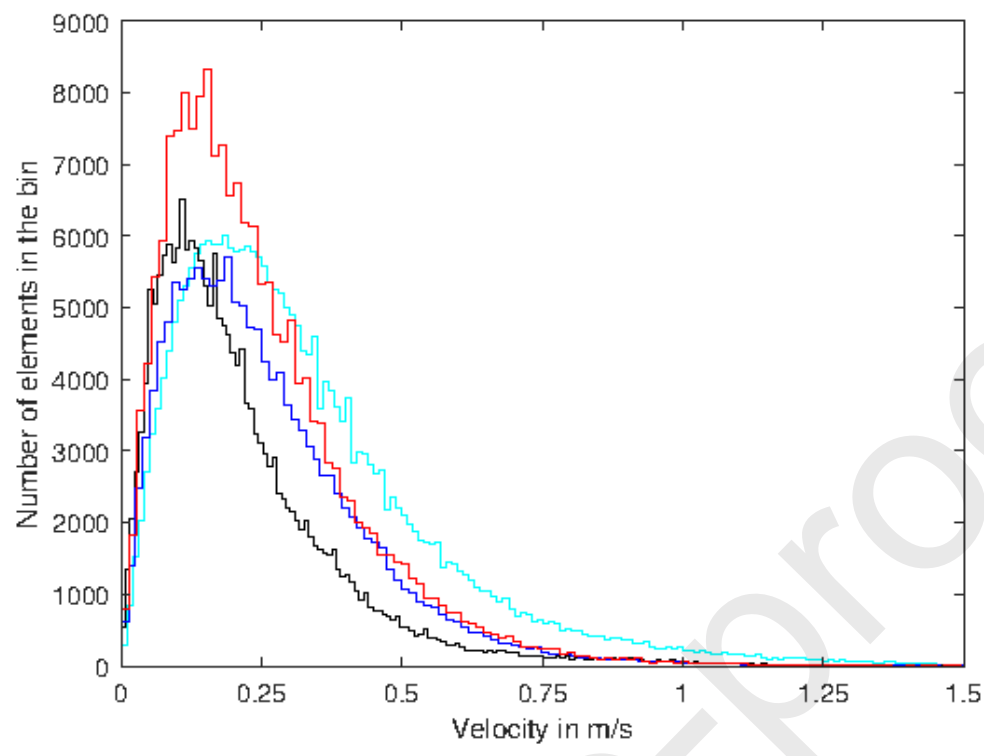

Fig. A.13: Same as Fig. 6 but when particles are reset every 10 days at the observed drifters locations. 

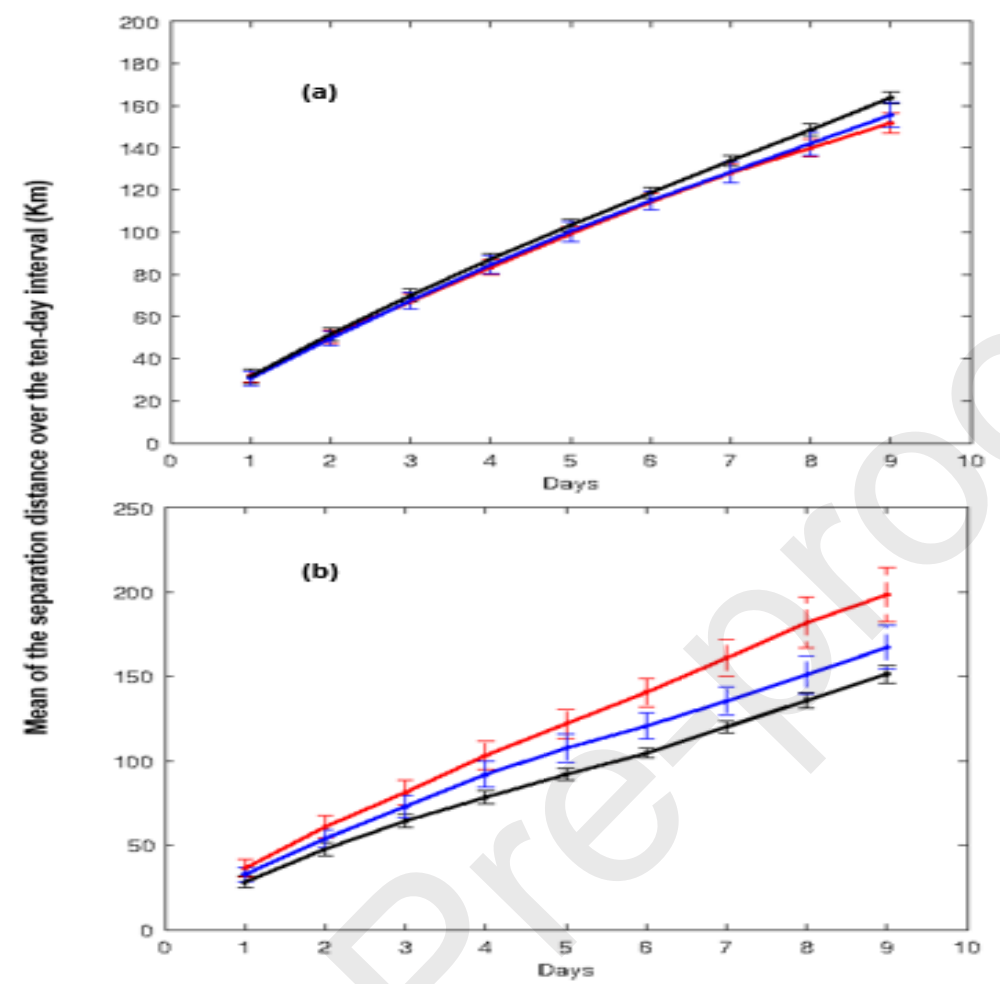

Fig. A.14: Mean of the separation distance over the ten-day interval when particles are reset every 10 days at the observed drifters locations. 

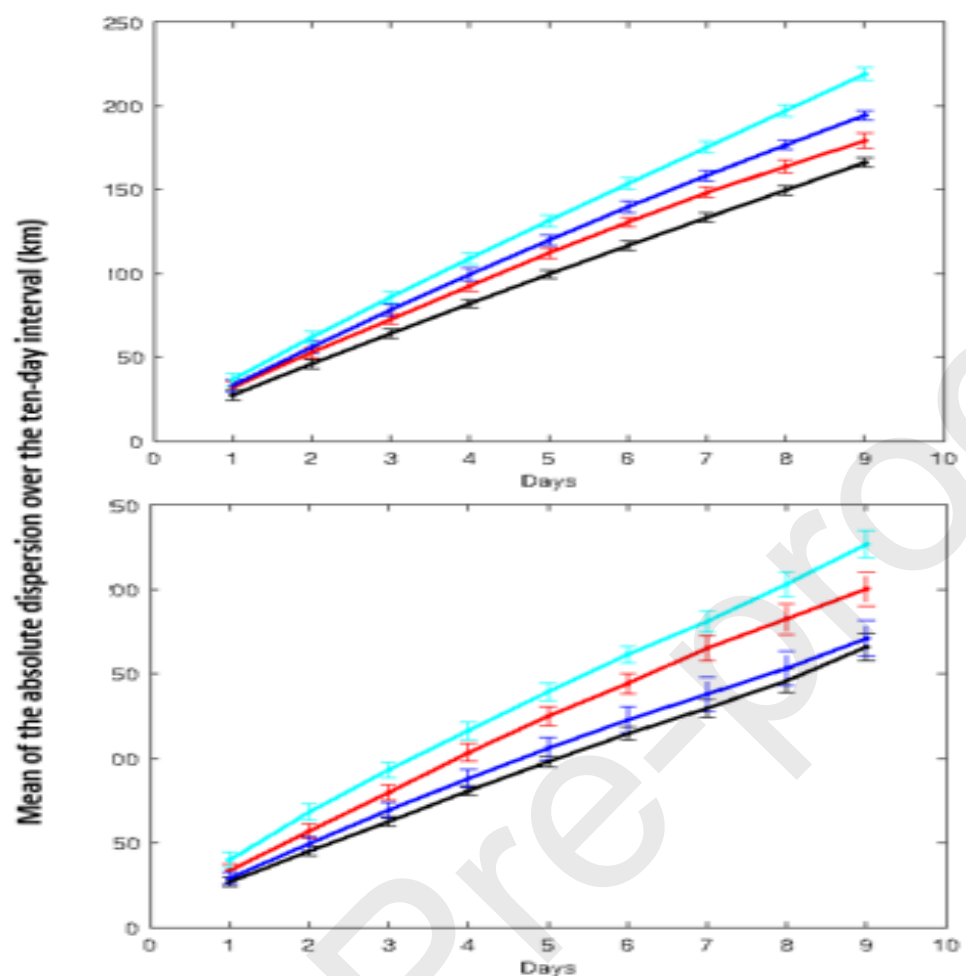

Fig. A.15: Mean of the absolute dispersion over the ten-day interval when particles are reset every 10 days at the observed drifters locations. 


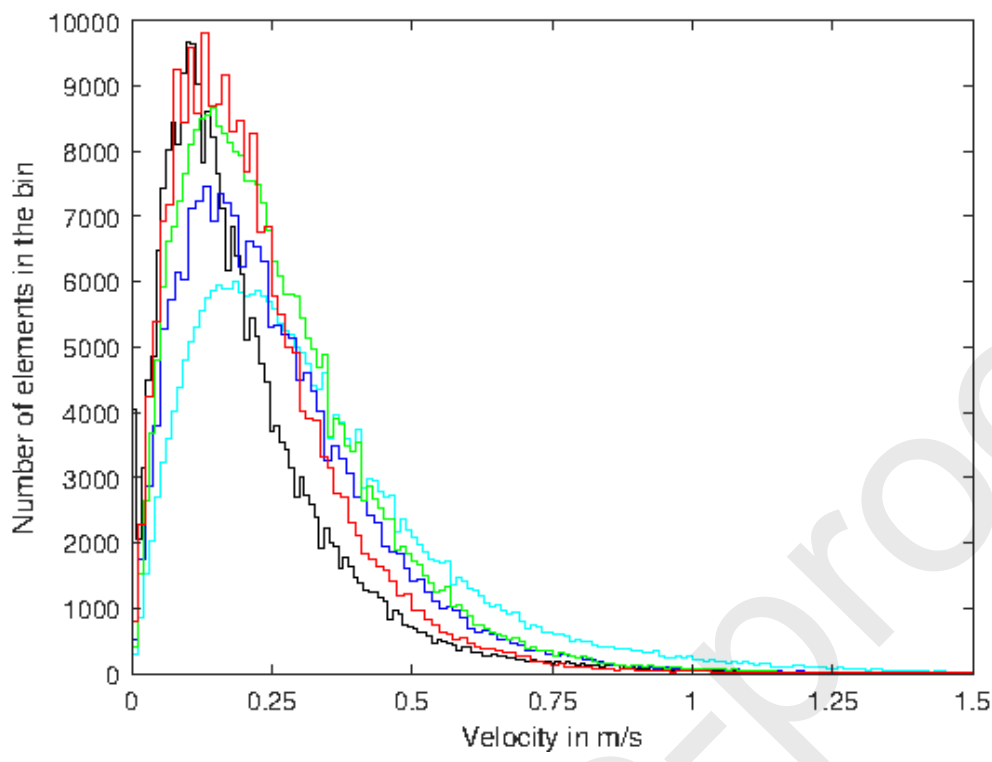

Fig. A.16: Same as Fig. 6 but with 3-hour output currents (green) as opposed to 1-day (blue) for GlobCurrent. 


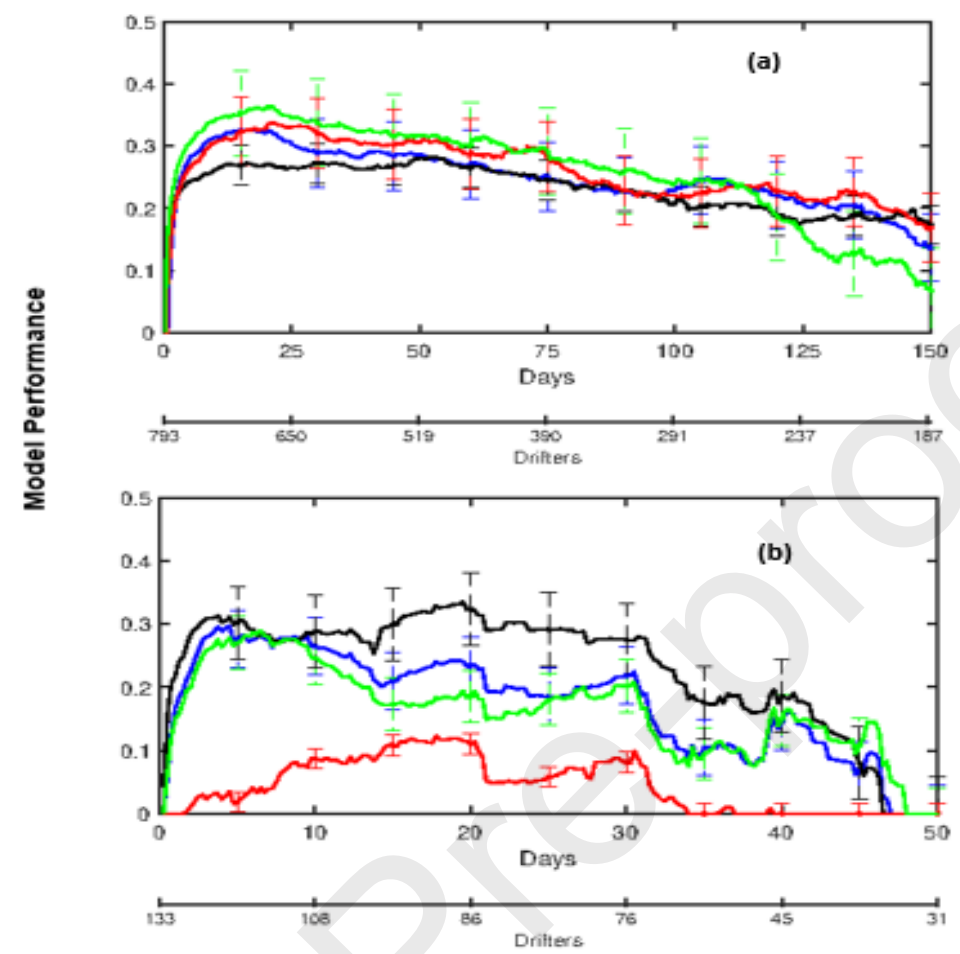

Fig. A.17: Same as Fig. 8 but with 3-hour output currents (green) as opposed to 1-day (blue) for GlobCurrent. 


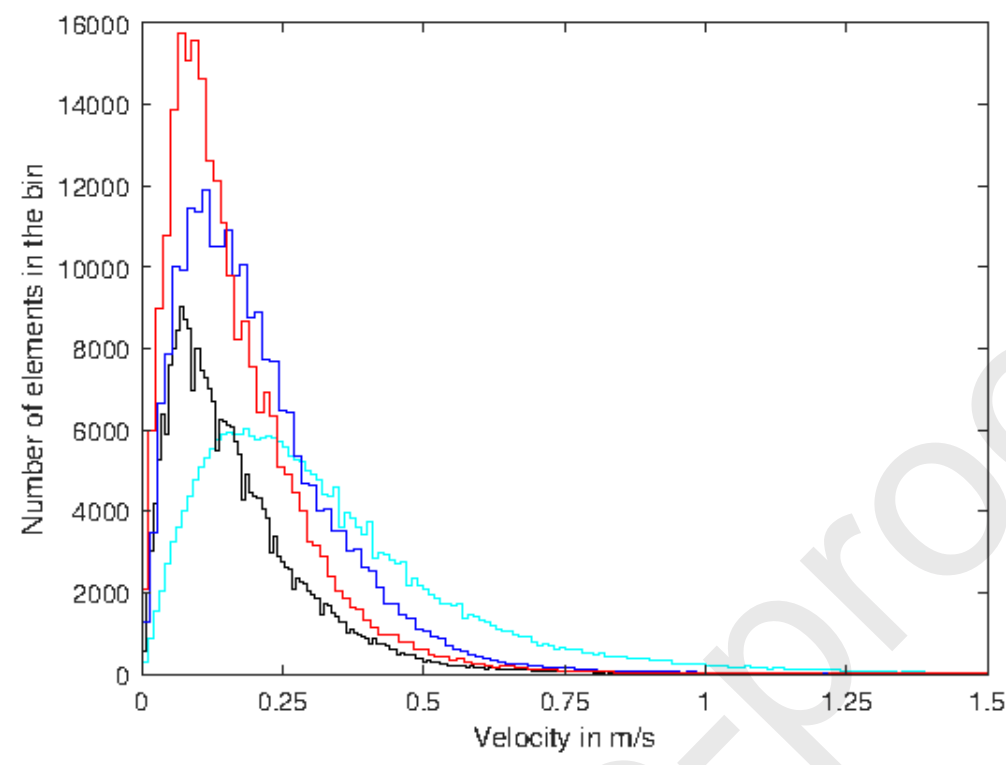

Fig. A.18: Same as Fig. 6 but using the barycenter of a cloud of 1,000 particles released at the observed drifters initial locations. 

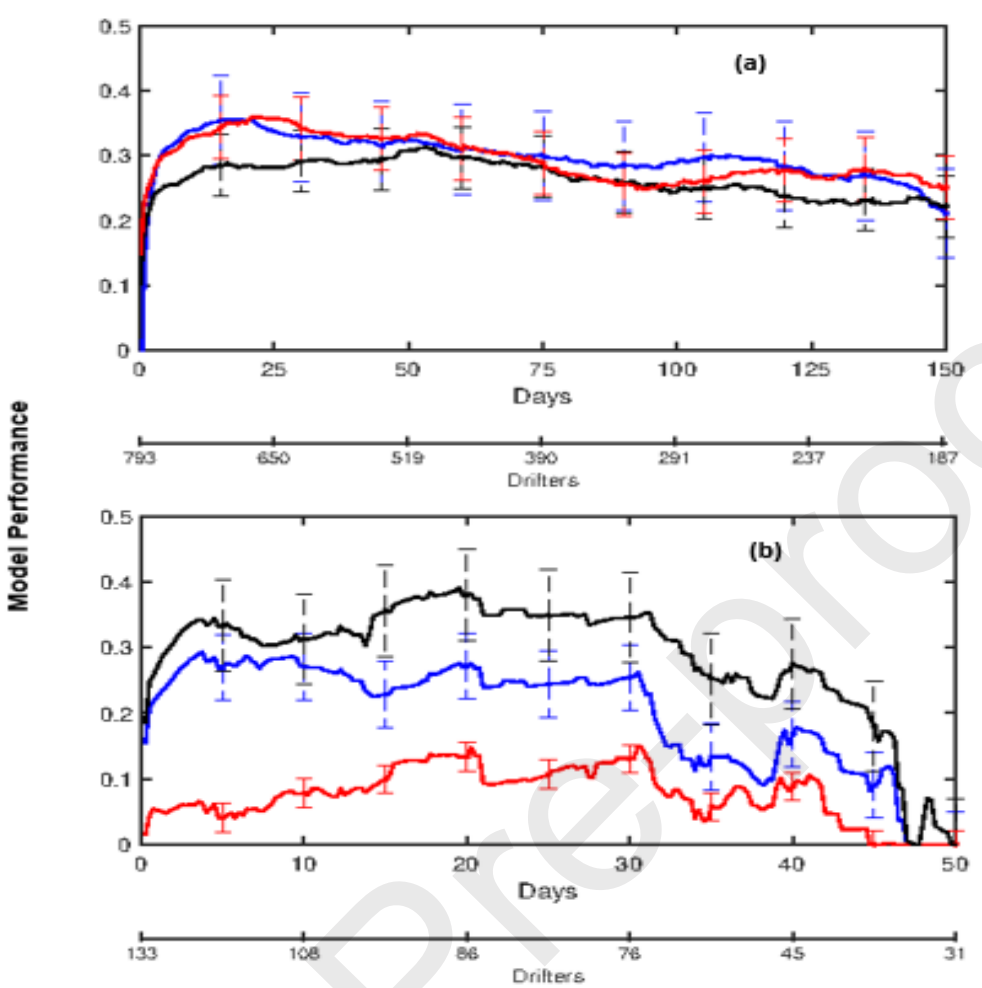

Fig. A.19: Same as Fig. 8 but using the barycenter of a cloud of 1,000 particles released at the observed drifters initial locations. 

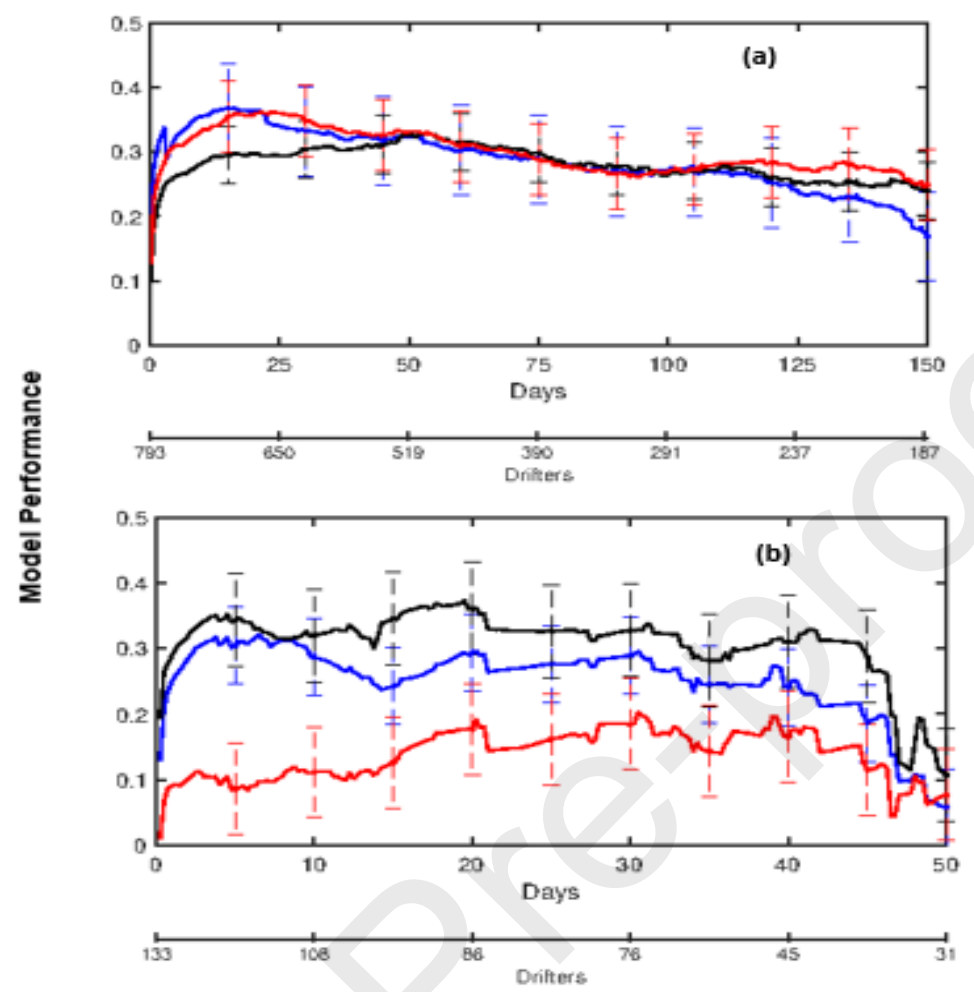

Fig. A.20: Same as Fig. A.19 but using the barycenter of a cloud of 1,000 particles released around (radius $\mathrm{R}=50 \mathrm{~km}$ ) observed drifters initial locations. 


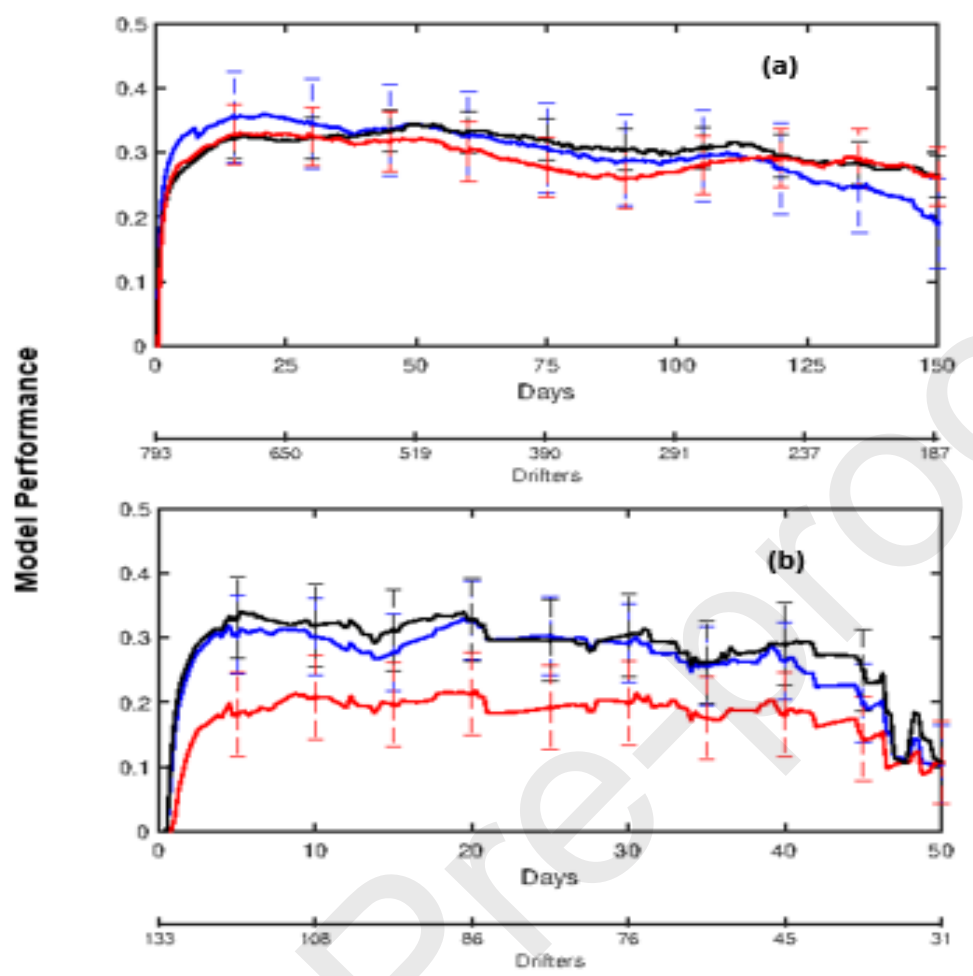

Fig. A.21: Same as Fig. A.20 but with $R=200 \mathrm{~km}$. 


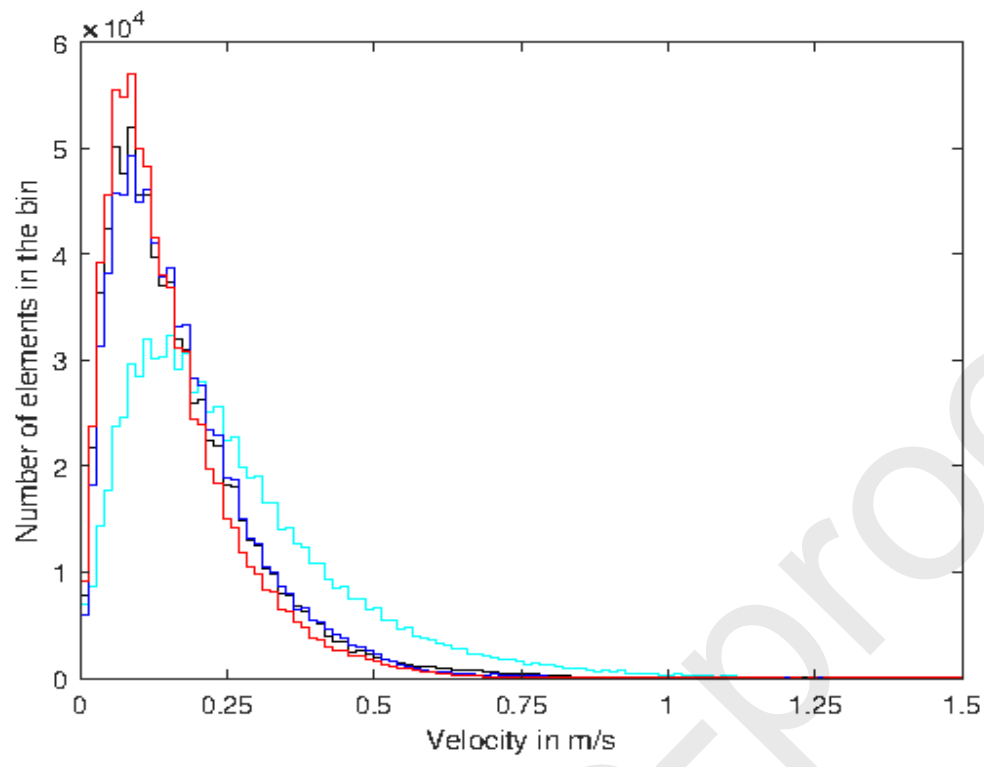

Fig. A.22: Same as Fig. 7 but using the barycenter of a cloud of 1,000 particles released at the observed FAD initial locations. 


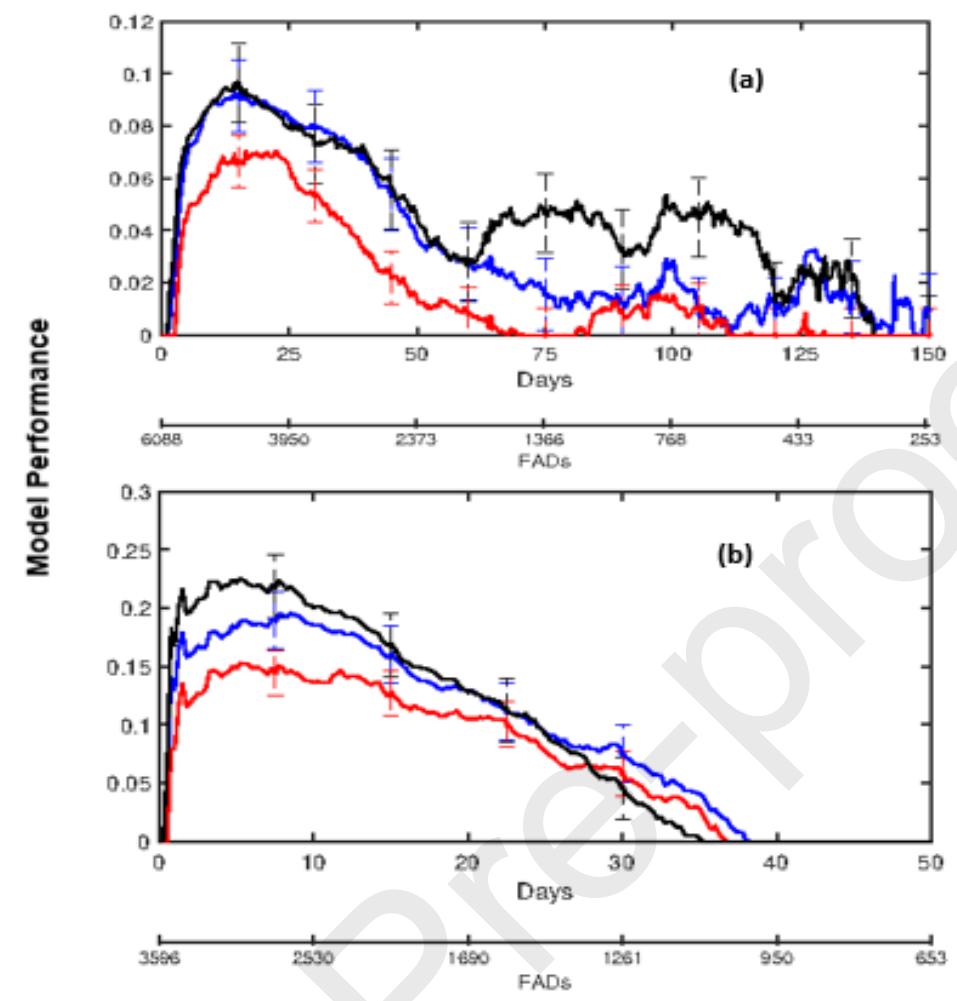

Fig. A.23: Same as Fig. 9 but using the barycenter of a cloud of 1,000 particles released at the observed FAD initial locations. 


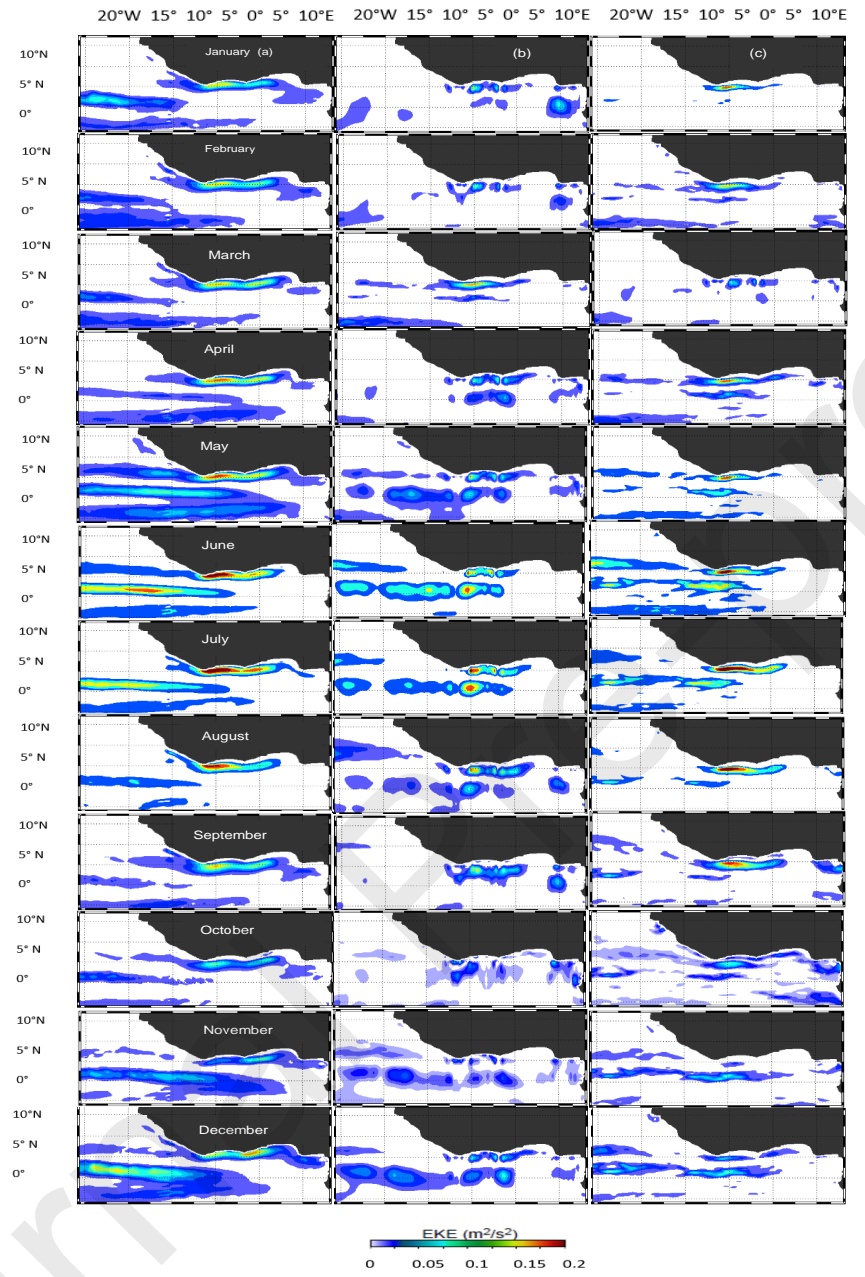

Fig. A.24: Monthly climatology of Eddy Kinetic Energy (EKE, $\mathrm{m}^{2} / \mathrm{s}^{2}$ ) over the Gulf of Guinea: (a) for CROCO, (b) for OSCAR and (c) for GlobCurrent. 


\section{References}

Aguedjou H, Dadou I, Chaigneau A, Morel Y, Alory G. Eddies in the Tropical Atlantic Ocean and their seasonal variability. Geophysical Research Letters, 2019;46(21):12156-12164.

Arnault S. Tropical Atlantic geostrophic currents and ship drifts. Journal of Geophysical Research: Oceans, 1987;92(C5):5076-5088.

Barron CN, Smedstad LF, Dastugue JM, Smedstad OM. Evaluation of ocean models using observed and simulated drifter trajectories: Impact of sea surface height on synthetic profiles for data assimilation. Journal of Geophysical Research: Oceans, 2007;112(C7).

Baske A, Gibbon J, Benn J, Nickson A. Estimating the use of drifting Fish Aggregation Devices (FADs) around the globe. PEW Environmental group. Technical Report; discussion paper, 8p; 2012.

Bedi K, Gómez-Ullate D, Izquierdo A, Montblanc TF. Validating Ocean General Circulation Models via Lagrangian Particle Simulation and Data from Drifting Buoys. In: International Conference on Computational Science. Springer; 2019. p. 253-264.

Beron-Vera FJ, LaCasce J. Statistics of simulated and observed pair separations in the Gulf of Mexico. Journal of Physical Oceanography, 2016;46(7):21832199.

Berta M, Bellomo L, Magaldi MG, Griffa A, Molcard A, Marmain J, Borghini M, Taillandier V. Estimating Lagrangian transport blending drifters with HF radar data and models: results from the TOSCA experiment in the Ligurian Current North Western Mediterranean Sea. Progress in oceanography, 2014;128:15-29. doi $10.1016 / \mathrm{j}$. pocean . 2014.08.004

Binet D. Climate and pelagic fisheries in the Canary and Guinea currents 19641993: The role of trade winds and the southern oscillation. Oceanologica Acta, 1997;20(1):177-190. 
Binet D, Marchal E. The large marine ecosystem of shelf areas in the Gulf of Guinea: long-term variability induced by climatic changes. Large marine ecosystems: stress, mitigation, and sustainability, 1993;:104-118.

Blanke B, Bonhommeau S, Grima N, Drillet Y. Sensitivity of advective transfer times across the North Atlantic Ocean to the temporal and spatial resolution of model velocity data: Implication for European eel larval transport. Dynamics of Atmospheres and Oceans, 2012;55:22-44.

Blanke B, Delecluse P. Variability of the tropical Atlantic Ocean simulated by a general circulation model with two different mixed-layer physics. Journal of Physical Oceanography, 1993;23(7):1363-1388.

Blanke B, Speich S, Madec G, Döös K. A global diagnostic of interocean mass transfers. Journal of Physical Oceanography, 2001;31(6):1623-1632.

Bonjean F, Lagerloef GS. Diagnostic model and analysis of the surface currents in the tropical Pacific Ocean. Journal of Physical Oceanography, 2002;32(10):2938-2954.

Bourlès B, Molinari R, Johns E, Wilson W, Leaman K. Upper layer currents in the Western Tropical North Atlantic (1989-1991). Journal of Geophysical Research: Oceans, 1999;104(C1):1361-1375.

Broecker W, Peng TH, Stuiver M. An estimate of the upwelling rate in the equatorial Atlantic based on the distribution of bomb radiocarbon. Jourㅁ nal of Geophysical Research: Oceans, 1978;83(C12):6179-6186. doi 10.1029/ JC083iC12p06179,

Bromhead D, Foster J, Attard R, Findlay J, Kalish J. A review of the impacts of fish aggregating devices (FADs) on tuna fisheries: Final Report to the Fisheries Resources Research Fund publ. Bureau of Rural Sciences, Australia 122pp, 2003;doi:url=https://nla.gov .au/nla .arc-55030. 
Caltabiano A, Robinson I, Pezzi L. Multi-year satellite observations of instability waves in the Tropical Atlantic Ocean. Ocean Science Discussions, 2005;2(1):135.

Carlson DF, Griffa A, Zambianchi E, Suaria G, Corgnati L, Magaldi MG, Poulain PM, Russo A, Bellomo L, Mantovani C, et al. Observed and mod560 eled surface Lagrangian transport between coastal regions in the Adriatic Sea with implications for marine protected areas. Continental Shelf Research, 2016;118:23-48.

Chang H, Huntley HS, Jr AK, Carlson DF, Mensa JA, Mehta S, Novelli G, Özgökmen TM, Fox-Kemper B, Pearson B, et al. Small-scale dispersion in

${ }_{565}$ the presence of Langmuir circulation. Journal of Physical Oceanography, 2019;49(12):3069-3085.

Choi J, Bracco A, Barkan R, Shchepetkin AF, McWilliams JC, Molemaker JM. Submesoscale dynamics in the northern Gulf of Mexico. Part III: Lagrangian implications. Journal of Physical Oceanography, 2017;47(9):2361-2376.

Dagestad KF, Röhrs J. Prediction of ocean surface trajectories using satellite derived vs. modeled ocean currents. Remote sensing of environment, 2019;223:130-142.

D'Asaro EA, Shcherbina AY, Klymak JM, Molemaker J, Novelli G, Guigand CM, Haza AC, Haus BK, Ryan EH, Jacobs GA, et al. Ocean convergence and 575 the dispersion of flotsam. Proceedings of the National Academy of Sciences, 2018;115(6):1162-1167.

Dauhajre DP, McWilliams JC, Renault L. Nearshore Lagrangian Connectivity: Submesoscale Influence and Resolution Sensitivity. Journal of Geophysical Research: Oceans, 2019;124(7):5180-5204.

${ }_{580}$ De Dominicis M, Bruciaferri D, Gerin R, Pinardi N, Poulain P, Garreau P, Zodiatis G, Perivoliotis L, Fazioli L, Sorgente R, Manganielloi C. A multimodel assessment of the impact of currents, waves and wind in modelling 
surface drifters and oil spill. Deep Sea Research Part II: Topical Studies in Oceanography, 2016;133:21-38. doi $10.1016 / \mathrm{j} . \mathrm{dsr} 2.2016 .04 .002$.

Döös K, Rupolo V, Brodeau L. Dispersion of surface drifters and modelsimulated trajectories. Ocean Modelling, 2011;39(3-4):301-10.

Drévillon M, Greiner E, Paradis D, Payan C, Lellouche JM, Reffray G, Durand E, Law-Chune S, Cailleau S. A strategy for producing refined currents in the Equatorial Atlantic in the context of the search of the AF447 wreckage.

Ducet N, Le Traon PY, Reverdin G. Global high-resolution mapping of ocean circulation from TOPEX/Poseidon and ERS-1 and -2. Journal of Geophysical Research: Oceans, 2000;105(C8):19477-19498.

Edwards K, Werner F, Blanton B. Comparison of observed and modeled drifter 610 trajectories in coastal regions: an improvement through adjustments for ob- 
served drifter slip and errors in wind fields. Journal of Atmospheric and Oceanic Technology, 2006;23(11):1614-1620. doi:10.1175/JTECH1933.1.

Elipot S, Lumpkin R, Perez RC, Lilly JM, Early JJ, Sykulski AM. A global surface drifter data set at hourly resolution. Journal of Geophysical Research: Oceans, 2016;121(5):2937-2966.

Fonteneau A, Chassot E, Bodin N. Global spatio-temporal patterns in tropical tuna purse seine fisheries on drifting fish aggregating devices (DFADs): Taking a historical perspective to inform current challenges. Aquatic Living Resources, 2013;26(1):37-48.

Fossette S, Putman NF, Lohmann KJ, Marsh R, Hays GC. A biologist's guide to assessing ocean currents: a review. Marine Ecology Progress Series, 2012;457:285-301.

Franco J, Dagorn L, Sancristobal I, Moreno G. Design of ecological FADs. Indian Ocean Tuna Commission Document. Technical Report; IOTC-2009-WPE 16; 2009.

Fratantoni DM, Richardson PL. The evolution and demise of North Brazil Current rings. Journal of Physical Oceanography, 2006;36(7):1241-1264.

Griffa A, Kirwan Jr A, Mariano AJ, Özgökmen T, Rossby HT. Lagrangian analysis and prediction of coastal and ocean dynamics. Cambridge University

${ }_{630} \quad$ Press, 2007.

Grodsky SA, Lumpkin R, Carton JA. Spurious trends in global surface

口 drifter currents. Geophysical Research Letters, 2011;38(10). doi 10.1029/ 2011GL047393.

Hansen DV, Poulain PM. Quality control and interpolations of WOCE-TOGA drifter data. Journal of Atmospheric and Oceanic Technology, 1996;13(4):900909. 
Hart-Davis MG, Backeberg BC, Halo I, van Sebille E, Johannessen JA. Assessing the accuracy of satellite derived ocean currents by comparing observed and virtual buoys in the Greater Agulhas Region. Remote Sensing of Environment, 2018;216:735-746.

Haza AC, Özgökmen TM, Griffa A, Garraffo ZD, Piterbarg L. Parameterization of particle transport at submesoscales in the Gulf Stream region using Lagrangian subgridscale models. Ocean Modelling, 2012;42:31-49.

He R, Liu Y, Weisberg RH. Coastal ocean wind fields gauged against the performance of an ocean circulation model. Geophysical research letters, 2004;31(14). doi:10.1029/2003GL019261

Hufnagl M, Payne M, Lacroix G, Bolle LJ, Daewel U, Dickey-Collas M, Gerkema T, Huret M, Janssen F, Kreus M, et al. Variation that can be expected when using particle tracking models in connectivity studies. Journal of sea research, 2017;127:133-149.

Huntley HS, Lipphardt B, Kirwan A, Hogan P. Surface drift predictions of the Deepwater Horizon spill: The Lagrangian perspective. 2010. p. OS33C-1485.

Imzilen T, Chassot E, Barde J, Demarcq H, Maufroy A, Roa-Pascuali L, Ternon JF, Lett C. Fish aggregating devices drift like oceanographic drifters in the near-surface currents of the Atlantic and Indian Oceans. Progress in oceanography, 2019;171:108-127.

Ivichev I, Hole L, Karlin L, Wettre C, Röhrs J. Comparison of operational oil spill trajectory forecasts with surface drifter trajectories in the Barents Sea. J Geol Geosci, 2012;1:105.

Johannessen J, Chapron B, Collard F, Rio M, Piollé J, Gaultier L, Quartly G, Shutler J, Raj R, Donlon C, Danielson R, Korosov A, Nencioli F, Kudryavtsev V, Roca M, Tournadre J, Larnicol G, Guitton G, Miller P, Warren M, Hansen MW. GlobCurrent: Multisensor synergy for surface current estimation. In: Proceedings of Living Planet Symposium. ESA; 2016. p. SP-740. 
Johnson ES, Bonjean F, Lagerloef GS, Gunn JT, Mitchum GT. Validation and error analysis of OSCAR sea surface currents. Journal of Atmospheric and Oceanic Technology, 2007;24(4):688-701.

Klein P, Lapeyre G. The oceanic vertical pump induced by mesoscale and submesoscale turbulence. Annual review of marine science, 2009;1:351-375.

${ }_{670}$ Koné V, Lett C, Penven P, Bourlés B, Djakouré S. A biophysical model of S. aurita early life history in the northern Gulf of Guinea. Progress in oceanography, 2017;151:83-96.

LaCasce J. Statistics from Lagrangian observations. Progress in Oceanography, $2008 ; 77(1): 1-29$.

675 Lacorata G, Palatella L, Santoleri R. Lagrangian predictability characteristics of an $\mathrm{O}$ cean $\mathrm{M}$ odel. Journal of Geophysical Research: Oceans, 2014;119(11):8029-8038.

Laurindo LC, Mariano AJ, Lumpkin R. An improved near-surface velocity climatology for the global ocean from drifter observations. Deep Sea Research Part I: Oceanographic Research Papers, 2017;124:73-92.

Lett C, Verley P, Mullon C, Parada C, Brochier T, Penven P, Blanke B. A Lagrangian tool for modelling ichthyoplankton dynamics. Environmental Modelling \& Software, 2008;23(9):1210-1214.

Liu Y, Weisberg RH. Evaluation of trajectory modeling in different dynamic regions using normalized cumulative Lagrangian separation. Journal of Geophysical Research: Oceans, 2011;116(C9). doi:10.1029/2010JC006837

Liu Y, Weisberg RH, Vignudelli S, Mitchum GT. Evaluation of altimetryderived surface current products using Lagrangian drifter trajectories in the eastern Gulf of Mexico. Journal of Geophysical Research: Oceans, 2014;119(5):2827-2842. doi:10.1002/2013JC009710. 
Liubartseva S, Coppini G, Lecci R, Creti S. Regional approach to modeling the transport of floating plastic debris in the Adriatic Sea. Marine pollution bulletin, 2016;103(1-2):115-127. doi:10.1016/j .marpolbul.2015.12.031.

Lumpkin R, Garzoli SL. Near-surface circulation in the tropical Atlantic Ocean. Deep Sea Research Part I: Oceanographic Research Papers, 2005;52(3):495518. doi:10.1016/j.dsr.2004.09.001.

Lumpkin R, Maximenko N, Pazos M. Evaluating where and why drifters die. Journal of Atmospheric and Oceanic Technology, 2012;29(2):300-308.

Lumpkin R, Pazos M. Measuring surface currents with surface velocity program drifters: the instrument, its data, and some recent results. Lagrangian analysis and prediction of coastal and ocean dynamics, 2007;2:39.

Maufroy A, Chassot E, Joo R, Kaplan DM. Large-scale examination of spatio-temporal patterns of drifting fish aggregating devices (dFADs) from tropical tuna fisheries of the Indian and Atlantic oceans. PloS one, 2015;10(5):e0128023. doi:10.1371/journal.pone. 0128023 .

Maufroy A, Kaplan DM, Bez N, De Molina AD, Murua H, Floch L, Chassot E. Massive increase in the use of drifting Fish Aggregating Devices (dFADs) by tropical tuna purse seine fisheries in the Atlantic and Indian oceans. ICES Journal of Marine Science, 2017;74(1):215-225.

Mbaye BC, Brochier T, Echevin V, Lazar A, Lévy M, Mason E, Gaye AT, Machu E. Do Sardinella aurita spawning seasons match local retention patterns in the Senegalese-Mauritanian upwelling region? Fisheries Oceanography, 2015;24(1):69-89.

McClean JL, Poulain PM, Pelton JW, Maltrud ME. Eulerian and Lagrangian statistics from surface drifters and a high-resolution POP simulation in the North Atlantic. Journal of Physical Oceanography, 2002;32(9):2472-2491.

McWilliams JC. Fluid dynamics at the margin of rotational control. Environmental fluid mechanics, 2008;8(5-6):441-449. 
Meyer I, Braby L, Krug M, Backeberg B. Mapping the ocean current strength and persistence in the Agulhas to inform marine energy development. In: Marine renewable energy,. Springer; 2017. p. 179-215.

Nieto K, Mélin F. Variability of chlorophyll-a concentration in the Gulf of Guinea and its relation to physical oceanographic variables. Progress in oceanography 2017;151:97-115.

725 Ohlmann JC, Mitarai S. Lagrangian assessment of simulated surface current dispersion in the coastal ocean. Geophysical Research Letters, 2010;37(17). doi:10.1029/2010GL044436.

Peliz A, Marchesiello P, Dubert J, Marta-Almeida M, Roy C, Queiroga H. A study of crab larvae dispersal on the Western Iberian Shelf: Physical processes. Journal of Marine Systems, 2007;68(1-2):215-236. doi:10.1016/j . jmarsys.2006.11.007.

Phillips JS, Escalle L, Pilling G, Gupta AS, van Sebille E. Regional connectivity and spatial densities of drifting fish aggregating devices, simulated from fishing events in the Western and Central Pacific Ocean. Environmental Research

735 Communications, 2019;1(5):055001.

Putman NF, He R. Tracking the long-distance dispersal of marine organisms: sensitivity to ocean model resolution. Journal of the Royal Society Interface, 2013;10(81):20120979.

Qin X, van Sebille E, Gupta AS. Quantification of errors induced by temporal resolution on Lagrangian particles in an eddy-resolving model. Ocean Modelling, 2014;76:20-30.

Richardson PL, Walsh D. Mapping climatological seasonal variations of surface currents in the tropical Atlantic using ship drifts. Journal of Geophysical Research: Oceans, 1986;91(C9):10537-10550.

745 Rio MH, Mulet S, Picot N. Beyond GOCE for the ocean circulation estimate: Synergetic use of altimetry, gravimetry, and in situ data provides new in- 
sight into geostrophic and Ekman currents. Geophysical Research Letters, 2014;41(24):8918-8925.

Scott G, Lopez J. The use of FADs in tuna fisheries. Directorate-general for Internal Policies, Policy Department B: Structural and cohesion policies, European Parliament. Technical Report; IP/B/PECH/IC/2013-123; 2014.

Scott RB, Ferry N, Drévillon M, Barron CN, Jourdain NC, Lellouche JM, Metzger EJ, Rio MH, Smedstad OM. Estimates of surface drifter trajectories in the equatorial Atlantic: a multi-model ensemble approach. Ocean Dynamics, 2012;62(7):1091-1109. doi: $10.1007 /$ s10236-012-0548-2.

Shchepetkin AF, McWilliams JC. The regional oceanic modeling system (ROMS): a split-explicit, free-surface, topography-following-coordinate oceanic model. Ocean modelling, 2005;9(4):347-404.

Sorgente R, Tedesco C, Pessini F, De Dominicis M, Gerin R, Olita A, Fazioli L, Di Maio A, Ribotti A. Forecast of drifter trajectories using a Rapid Environmental Assessment based on CTD observations. Deep Sea Research Part II: Topical Studies in Oceanography, 2016;133:39-53.

Swearer SE, Treml EA, Shima JS. A Review of Biophysical Models of Marine Larval Dispersal. volume 57. CRC Press, 2019.

Taylor G. Diffusion by continuous movements. volume 20; 1921. p. 196-212.

Thomas LN, Tandon A, Mahadevan A. Submesoscale processes and dynamics. Ocean modeling in an Eddying Regime, 2008;177:17-38.

Van Sebille E, Griffies SM, Abernathey R, Adams TP, Berloff P, Biastoch A, Blanke B, Chassignet EP, Cheng Y, Cotter CJ, et al. Lagrangian ocean analysis: Fundamentals and practices. Ocean Modelling, 2018;121:49-75.

Vignudelli S, Kostianoy AG, Cipollini P, Benveniste J. Coastal altimetry. Springer Science \& Business Media, 2011. 
Villas Boas AB, Ardhuin F, Ayet A, Bourassa MA, Chapron B, Brandt P, Cornuelle BD, Farrar JT, Fewings MR, Fox-Kemper B, et al. Integrated observations and modeling of global winds, currents, and waves: requirements and challenges for the next decade. Frontiers in Marine Science, 2019;6:425. doi:10.3389/fmars.2019.00425, 


\section{Highlights}

- Assessement of the accuracy of a Lagrangian model forced with different velocity fields using drifters and Fish Aggregating Devices (FADs).

- CROCO, OSCAR and GlobCurrent have the same performance.

- CROCO is better in the Gulf of Guinea than the satellite derived currents.

- The simulations underestimate the drifters and FADs velocities.

- FADs may not be appropriate to use for corroborating Lagrangian simulations. 